\title{
Fibroblast GATA-4 and GATA-6 promote myocardial adaptation to pressure overload by enhancing cardiac angiogenesis
}

\author{
Gesine M. Dittrich ${ }^{1,2,8} \cdot$ Natali Froese $^{1} \cdot$ Xue Wang $^{1,3} \cdot$ Hannah Kroeger $^{1} \cdot$ Honghui Wang $^{1} \cdot$ Malgorzata Szaroszyk $^{1} \cdot$ \\ Mona Malek-Mohammadi ${ }^{2,8} \cdot$ Julio Cordero $^{4} \cdot$ Merve Keles $^{2} \cdot$ Mortimer Korf-Klingebiel $^{1} \cdot$ Kai C. Wollert $^{1}$. \\ Robert Geffers ${ }^{5} \cdot$ Manuel Mayr $^{6} \cdot$ Simon J. Conway ${ }^{7} \cdot$ Gergana Dobreva $^{4,8} \cdot$ Johann Bauersachs ${ }^{1}$. \\ Joerg Heineke ${ }^{1,2,8,9}$
}

Received: 31 July 2020 / Accepted: 15 March 2021 / Published online: 19 April 2021

(c) The Author(s) 2021

\begin{abstract}
Heart failure due to high blood pressure or ischemic injury remains a major problem for millions of patients worldwide. Despite enormous advances in deciphering the molecular mechanisms underlying heart failure progression, the cell-type specific adaptations and especially intercellular signaling remain poorly understood. Cardiac fibroblasts express high levels of cardiogenic transcription factors such as GATA-4 and GATA-6, but their role in fibroblasts during stress is not known. Here, we show that fibroblast GATA-4 and GATA-6 promote adaptive remodeling in pressure overload induced cardiac hypertrophy. Using a mouse model with specific single or double deletion of Gata4 and Gata6 in stress activated fibroblasts, we found a reduced myocardial capillarization in mice with Gata4/6 double deletion following pressure overload, while single deletion of Gata4 or Gata6 had no effect. Importantly, we confirmed the reduced angiogenic response using an in vitro co-culture system with Gata4/6 deleted cardiac fibroblasts and endothelial cells. A comprehensive RNA-sequencing analysis revealed an upregulation of anti-angiogenic genes upon Gata4/6 deletion in fibroblasts, and siRNA mediated downregulation of these genes restored endothelial cell growth. In conclusion, we identified a novel role for the cardiogenic transcription factors GATA-4 and GATA-6 in heart fibroblasts, where both proteins act in concert to promote myocardial capillarization and heart function by directing intercellular crosstalk.
\end{abstract}

Keywords Cardiac remodeling $\cdot$ Fibroblast $\cdot$ Angiogenesis $\cdot$ Intercellular crosstalk

Gesine M. Dittrich, Natali Froese, and Xue Wang contributed equally to this work.

Joerg Heineke

Joerg.Heineke@medma.uni-heidelberg.de

1 Department of Cardiology and Angiology, Hannover Medical School, 30625 Hannover, Germany

2 Department of Cardiovascular Physiology, European Center for Angioscience (ECAS), Medical Faculty Mannheim of Heidelberg University, 68167 Mannheim, Germany

3 Shanghai Tianyou Hospital Affiliated To Tongji University, Shanghai 200333, China

4 Department of Anatomy and Developmental Biology, European Center for Angioscience (ECAS), Medical Faculty Mannheim of Heidelberg University, 68167 Mannheim, Germany
5 Genome Analytics, Helmholtz Center for Infection Research, 38124 Braunschweig, Germany

6 King's British Heart Foundation Centre, King's College London, London, UK

7 HB Wells Center for Pediatric Research, Indiana University School of Medicine, Indianapolis, IN 46202, USA

8 German Center for Cardiovascular Research (DZHK), Partner site Heidelberg/Mannheim, Germany

9 Cardiovascular Physiology, European Center for Angioscience (ECAS), Medizinische Fakultät Mannheim, Universität Heidelberg, Ludolf-Krehl-Str. 7-11, 68167 Mannheim, Germany 


\section{Introduction}

With continuous increase of life expectancy, preventing the progression of cardiovascular diseases has become the major challenge to preserve a high quality of life in the prolonged life span. Despite enormous efforts to improve preventive and therapeutic medical interventions, cardiovascular diseases remain the main cause of hospital admissions and death in developed countries [42]. Current treatment approaches for heart failure target predominantly cardiac myocytes as main responsible cell type for disease progression. Indeed, in response to pathological overload or ischemia, cardiomyocytes exert profound changes in gene expression, cellular hypertrophy and alterations in excitation contraction coupling that aggravate heart failure [13]. However, a new paradigm emerged in recent years, whereby also other cardiac cell types, especially endothelial cells, inflammatory cells and fibroblasts are on one hand strongly influenced by pathological insults and on the other hand heavily affect the disease process by interacting among each other and with cardiomyocytes [41]. How this crosstalk between different cardiac cell types is regulated, which mediators are involved, and how it affects the heart's response to overload remains in large parts elusive.

Cardiac fibroblasts are among the non-myocytes that are increasingly recognized for their versatile function in the heart during pathological stress. While they were long neglected as sole provider of extracellular matrix, recent studies revealed that fibroblasts promote cardiomyocyte proliferation during development, promote adaptation through the secretion of IGF-1, impact hypertrophy in adult mice during pressure overload and regulate cardiac immune cell recruitment as well as scar remodeling after myocardial infarction [15, 16, 32, 34, 39]. Interestingly, cardiac fibroblasts exert a unique transcriptome, because they express high levels of cardiogenic transcription factors, such as Tbx20, Gata4, Gata6, and Hand2, which are all completely absent in skin fibroblasts. This indicates a specific differentiation pattern of cardiac fibroblasts designated to their operational area in the heart [8]. The functional impact of the cardiogenic gene program in myocardial fibroblasts, for example during myocardial overload, however, remains unknown.

The GATA family of transcription factors is divided into two groups based on their expression patterns, where GATA-1/-2/-3 are mainly found in the hematopoietic lineage, while GATA-4/-5/-6 are expressed in mesodermal derived tissues [26, 27]. In the developing and adult heart, the transcription factors GATA-4 and GATA- 6 are important regulators for the expression of cardiac genes. Combined global loss of GATA-4 and GATA- 6 prevents cardiomyocyte differentiation in early embryonic development resulting in acardia and embryonic death [51]. Cardiomyocyte specific deletion of GATA-4 or GATA-6 in adult mice leads to heart failure during pathological pressure overload [28, 44]. Both factors exert in part redundant functions in cardiac myocytes during stress, as they both promote cardiac hypertrophy and preserve heart function during overload. On the other hand, they contribute unique regulatory aspects for cellular gene-expression: GATA-4, but not GATA-6, for instance, drives a paracrine gene-program in cardiomyocytes to induce angiogenesis in adjacent endothelial cells [12, 43].

In the current study, we focused on the role of GATA-4 and GATA- 6 as part of the cardiogenic gene-program in cardiac fibroblasts. We generated a mouse model of single and compound deletion of both factors in activated fibroblasts. We demonstrate here that single deletion of GATA-4 or GATA-6 in fibroblasts had no effect, while their compound deletion reduced the myocardial angiogenic response and thereby impaired heart function during cardiac pressure overload. Comprehensive RNA-sequencing from isolated heart fibroblasts lacking either Gata4, Gata6 or both, revealed upregulation of several anti-angiogenic factors like Angpt4, Thbs1, and Cd36 upon Gata4/6 double deletion. Importantly, the anti-angiogenic effects of Gata $4 / 6$ depleted fibroblasts were blunted by siRNA mediated downregulation of the fibroblast derived angiogenic inhibitors. Hence, we propose that the cardiogenic gene-program in heart fibroblasts maintains the high capillary density in the myocardium during pressure overload by directing intercellular communication towards endothelial cells.

\section{Materials and methods}

\section{Animal experiments}

To obtain mice with fibroblast-specific Gata4, Gata6 or Gata4/6 deletion, previously described Gata $4^{f l o x} / f o x$ mice $\left(\right.$ Gata4 $\left.^{\text {tml.1Sad }}\right)$ [48] and Gata6 ${ }^{\text {flox/flox }}$ mice $\left(\right.$ Gata6 $\left.^{\text {tm2.1Sad }}\right)$ [37] were interbred to obtain Gata $4 / 6^{f l o x / f l o x}$ mice, as well as with mice expressing the Cre recombinase linked to a partial Postn promoter, Tg(Postn-Cre) ISjc [23]. Littermate Gata $^{\text {flox/flox }}$, Gata6 $6^{\text {flox/flox }}$ and Gata $4 / 6^{\text {flox/flox }}$ mice were used as controls.

Pressure overload was induced in 8-10-week-old mice by constriction of the transverse aorta following standard procedures [11, 49]. All animal procedures were approved by the local state authorities (33.14-42502-04-13/1159).

Transverse aortic constriction (TAC) was induced in 8-10 week-old mice following standard procedure and maintained for 2 weeks (short TAC) or 6 weeks (long TAC) as indicated in the figures. Anesthesia was induced with isoflurane in an induction chamber with $3 \%$ and maintained at 
$2 \%$ via mask ventilation. Analgesia was provided by subcutaneous injection. After secured tracheal intubation, the aortic arch was visualized through partial upper thoracotomy and a 7-0 silk ligature was tied around a 27-gauge needle between the right brachiocephalic and left common carotid arteries. In sham treated animals, the ligation was not tied. During surgery, the animals were placed on a heating pad connected to a temperature controller to maintain body temperature. Postoperative analgesia was additionally provided in the drinking water.

\section{Echocardiography}

Mice were anesthetized with $4 \%$ isoflurane in an induction chamber and placed on a heating pad to keep body temperature at $37{ }^{\circ} \mathrm{C}$. Anesthesia was maintained with $1-2 \%$ isoflurane through a mask. Echocardiography was performed in short and long axis views using the Vevo 770 Visualsonics system. Quantification of cardiac function was performed using the cardiac package provided with the Vevo software.

\section{Histology}

For organ harvesting, mice were sacrificed and whole hearts were immediately removed from the chest cavity, relaxed in $0.5 \mathrm{M} \mathrm{KCl}$, washed in cold PBS, transversely dissected at the midventricular level and immediately embedded in TissueTek OCT compound (Sakura). Slices of $12 \mu \mathrm{m}$ thickness were stained with Picro Sirius red following the standard protocol. Fibrosis was quantified as the fraction (in \%) of fibrotic tissue (stained in red) per total area of the myocardium using Adobe Photoshop imaging software. Perivascular fibrosis ratio (PFR) was determined as perivascular fibrotic area per vessel area using Adobe Photoshop imaging software.

\section{Immunofluorescence staining}

Immunofluorescence staining was performed on $7 \mu \mathrm{m}$ OCT cryosections. Slides were fixed with $4 \%$ PFA for $20 \mathrm{~min}$, permeabilized in $0.3 \%$ Triton-X for 20 min and blocked in $3 \%$ BSA for at least $1 \mathrm{~h}$ at room temperature. Each step was followed by three washing steps in PBS. Slides were then serially incubated with primary and secondary antibodies and mounted with Vectashield Mounting Medium with DAPI. The following primary antibodies were used: antiGATA-4 (1:50, Santa Cruz, sc-1237), anti-GATA-6 (1:20, $\mathrm{R}$ and D Systems, AF1700), anti-PDGFR- $\alpha$ (1:50, R and D Systems, AF1062), and anti-alpha smooth muscle Actin (1:400, Abcam, ab7817). Secondary antibodies (Alexa Fluor 488 and 555) anti-goat were used in a 1:200 dilution, antimouse (Alexa Fluor 555) in a 1:800 dilution.
Staining of the cell membrane and capillaries was performed with wheat germ agglutinin Texas red (Invitrogen, w21405) and fluorescein-labelled Isolectin B4 (IB4, Vector laboratories, FL-1201), respectively, according to the manufacturer's protocols. The ratio of IB4-stained capillaries per cardiomyocyte was assessed in three high power fields ( $200 \times$ magnification) per heart to determine capillary density. Images were acquired with an Axiovert microscope (Carl Zeiss, Jena, Germany). Whole heart brightfield and fluorescence images were acquired on a Zeiss Axio Scan System.

\section{Cell culture}

Human umbilical vein endothelial cells (HUVEC) and human cardiac microvascular endothelial cells (HCMEC) were purchased from PromoCell and cultured in Endothelial Cell Growth Medium (PromoCell) supplemented with growth factor cocktail containing FCS $2 \%$, ECGS $0.4 \%$, EGF $0.1 \mathrm{ng} / \mathrm{ml}$, bFGF $1 \mathrm{ng} / \mathrm{ml}$, Heparin $90 \mu \mathrm{g} / \mathrm{ml}$, and Hydrocortisone $1 \mu \mathrm{g} / \mathrm{ml}$. Neonatal rat ventricular fibroblasts were isolated from 1 to 3 day-old Sprague-Dawley rats and separated from cardiomyocytes by Percoll density gradient centrifugation as previously described [7, 50]. Isolated fibroblasts were cultured in DMEM containing 10\% FCS and antibiotics, until they were switched to media with $2 \%$ FCS or no FCS for experiments.

Transfection of rat cardiac fibroblasts was performed at $80 \%$ confluency after a maximum of two passages. $100 \mathrm{nM}$ of siRNA (siGATA4, J-090725-09-0010, Dharmacon; siGATA6, J-080135-13-0010, Dharmacon; siCD36, SASI_ Rn02_00264778, Sigma-Aldrich; siAngp4, J-09301009-0002, Dharmacon; neg. Ctrl, AM4635, Ambion) were incubated for 20 min with $32 \mu \mathrm{l}$ Lipofectamine 2000 in OptiMEM before the mixture was added to the cells for $5 \mathrm{~h}$. Subsequently the medium was changed to DMEM $2 \%$ FCS and cells were cultured for $48 \mathrm{~h}$ before conducting experiments.

Scratch assays were performed in 24-well plates after HUVECs or HCMECs reached $>90 \%$ confluency. The cell monolayer was scraped in a straight line with a p200-pipet tip to create a "scratch injury". The debris was removed by washing the cells once with PBS and fresh medium was added together with transfected fibroblasts cultured in permeable inserts or recombinant protein (thrombospondin-1 human, $50 \mathrm{nM}$, ECM002 Sigma; human angiopoietin-4, $50 \mathrm{ng} / \mathrm{ml}, 964-\mathrm{AN}-025 \mathrm{R}$ and D Systems) as indicated in the figure. Pictures were taken immediately after scratch, as well as $6 \mathrm{~h}$ and $10 \mathrm{~h}$ later. The scratch area was analyzed using ImageJ software and migration was calculated as the difference in cell-free area after 6 or $10 \mathrm{~h}$ compared to $0 \mathrm{~h}$ relative to the initial scratch area.

Tube formation assay was performed in matrigel coated 96-well plates. HUVECs were either co-cultured with 
transfected fibroblasts or treated with recombinant thrombospondin- 1 or angiopoietin 4 (concentration as indicated above). Pictures were taken after 8 and $24 \mathrm{~h}$ with 50-fold magnification and closed circular structures were quantified as tubes using ImageJ software.

\section{Isolation of murine cardiac cells}

For culture, cardiac fibroblasts were isolated from 6 to

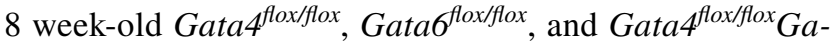
ta $6^{\text {flox/flox }}$ mice as previously described [34]. Whole hearts without atria were quickly cut into small pieces in ice-cold PBS. Digestion was performed using Liberase TH (Roche) with SADO buffer mix solution (20 mM HEPES-NaOH (Roth, Nr. 9105, pH 7.6), 130 mM NaCl (Roth, Nr. 9265), $3 \mathrm{mM} \mathrm{KCl}$ (Roth, Nr. 6781), 1 mM NaH2PO4 (Sigma, Nr. S5011), 4 mM Glucose (Roth, Nr. HN06), 3 mM MgSO4 (Roth, Nr. 2278) in sterile, filtered dH20). The digested cell solution was plated and after $3 \mathrm{~h}$ washed once with PBS and changed to DMEM supplemented with $10 \%$ FCS. Isolated fibroblasts were infected with AdCre or Ad $\beta$-Gal for $3 \mathrm{~h}$ and after two washing steps with PBS cultured in DMEM supplemented with $2 \%$ FCS for $48 \mathrm{~h}$. Cells were passaged two times at maximum before harvesting.

For immediate RNA or protein-isolation, cardiac fibroblasts and cardiac endothelial cells were isolated from hearts of adult mice using CD146 microbeads and feeder removal microbeads with MACS (magnetic cell separation) technology from Miltenyi Biotec.

Adult ventricular cardiomyocytes were isolated as previously described using a Langendorff system [24].

\section{RNA isolation and deep-sequencing analysis}

RNA from murine cardiac fibroblasts was isolated using the NucleoSpin RNA kit (Macherey-Nagel) according to the manufacturer's protocol. Further analysis was performed at the Helmholtz Center for Infection Research in Braunschweig. Quality and integrity of total RNA were controlled on the Agilent Technologies 2100 Bioanalyzer. The RNASeq library was generated from 500 to $1000 \mathrm{ng}$ total RNA using Dynabeads mRNA DIRECT Micro Purification Kit (Thermo Fisher Scientific) for mRNA purification followed by ScriptSeq v2 RNA-Seq Library Preparation Kit (Epicentre) according to the manufacturers' protocols. The libraries were sequenced on Illumina HiSeq2500 using TruSeq SBS Kit v3-HS (50 cycles, single-ended run) with an average of $3 \times 10^{7}$ reads per RNA sample. Before alignment to the reference (mm10), each sequence was trimmed on base call quality and sequencing adapter contamination using the Trim Galore! wrapper tool (http://github.com/felixkrueger/trimg alore). Reads shorter than $20 \mathrm{nt}$ were removed from FASTQ files. Trimmed reads were aligned to the reference using the short-read aligner STAR (https://code.google.com/p/ rna-star/). Feature counts were determined using R package "Rsubread". Only genes showing counts greater 5 at least two times across all samples were considered for further analysis (data cleansing). Gene annotation was done by $\mathrm{R}$ package "bioMaRt". Library size normalized counts (cpm counts per million) were $\log 2$ transformed and further normalized according to 50th percentile (quartile normalization using edgeR). Differential gene expression was calculated by R package "edgeR". Differentially expressed genes were selected with $0.5<$ fold change $>2$ and FDR $<0.05$. GO biological process clusters from different groups of genes were performed by Metascape [52]. Cluster relations were visualized in a network plot using cytoscape [35]. Heatmaps of differentially regulated genes were generated by using heatmap. 2 function in ggplot2 library in R. Our data set of RNA-Seq data is deposited in the National Center for Biotechnology Information's Gene Expression Omnibus database under accession number GSE155358.

\section{Quantitative real-time PCR}

Total RNA from fibroblasts of adult mouse hearts was isolated using the NucleoSpin RNA II Kit (Macherey Nagel) following the manufacturer's protocol. cDNA was generated using the Maxima H Minus First Strand cDNA Synthesis Kit (Thermo Fisher Scientific) and quantitative PCR was performed following standard procedures. Gene-expression was normalized to Rpl7 or Gapdh mRNA expression as indicated in the figure legend. Absolute quantification of Gata factor mRNA was based on standard curves with plasmids containing the full-length Gata sequences. Primer sequences are provided in Supplemental Table 1.

\section{Western blot}

Protein was extracted from fibroblasts of adult mouse hearts or whole heart tissue of Gata4/6-Per-Cre or Gata4/6 control mice as indicated, separated on an SDS-polyacrylamide gel under reduced denaturing conditions and subsequently blotted onto a PVDF membrane following standard procedures. Applied primary antibodies were anti-GATA-4 (1:1000, Santa Cruz, sc-1237), anti-GATA-4 (1:100, Santa Cruz, sc-25310), anti-GATA-6 (1:1000, R and D systems, AF1700) anti-GAPDH (1:3000, Fitzgerald, 10R-G109a) or anti-Actin (1:10,000, Sigma-Aldrich, A2066). Protein levels were quantified using Quantity One software (Bio-Rad).

\section{Extracellular matrix isolation and proteomic analysis}

Enrichment of extracellular matrix proteins was performed as previously described $[1,2]$. Heart tissue samples of 
Gata4/6-Per-Cre or Gata4/6 control mice were sequentially incubated with $0.5 \mathrm{M} \mathrm{NaCl}(1 \mathrm{~h}), 0.1 \% \mathrm{SDS}(16 \mathrm{~h})$ and $4 \mathrm{M}$ guanidine hydrochloride (48 hours). After precipitation of $\mathrm{GuHCl}$ extracts, protein samples were enzymatically deglycosylated and subjected to in-solution trypsin digestion. Digested peptides from $\mathrm{GuHCl}$ extracts were injected for liquid chromatography-tandem mass spectrometry (LCMS/MS) analysis onto a Q Exactive HF mass spectrometer (Thermo Fisher Scientific) for discovery proteomics. PC analysis was achieved using factoextra package, and visualized with ggplot 2 library in R. A clustered heatmap that indicates significantly different protein levels of main ECM components was created by pheatmap library in $\mathrm{R}$.

\section{Statistical analysis}

Data are presented as mean \pm SD. The investigators were blinded for mouse genotype during surgery, echocardiography, organ weight determination, and all histological and immunofluorescence quantifications. For comparison of two groups, unpaired two-tailed Student's $t$ test was used to determine statistical significance. For comparison of more than two groups, statistical significance was determined using one-way ANOVA (with Dunnett's multiple-comparisons test or Tukey's multiple-comparisons test) for one independent variable and two-way ANOVA (with Sidak's multiple-comparisons test) for two independent variables with GraphPad Prism 7 software. $P$ values less than 0.05 were considered statistically significant.

\section{Results}

\section{Among the GATA transcription factors, Gata4 and Gata6 show the highest expression in cardiac fibroblasts}

First, we analyzed the mRNA expression levels of all GATA family transcription factors in cardiac fibroblasts isolated from adult mice. The results from bulk RNA-sequencing of

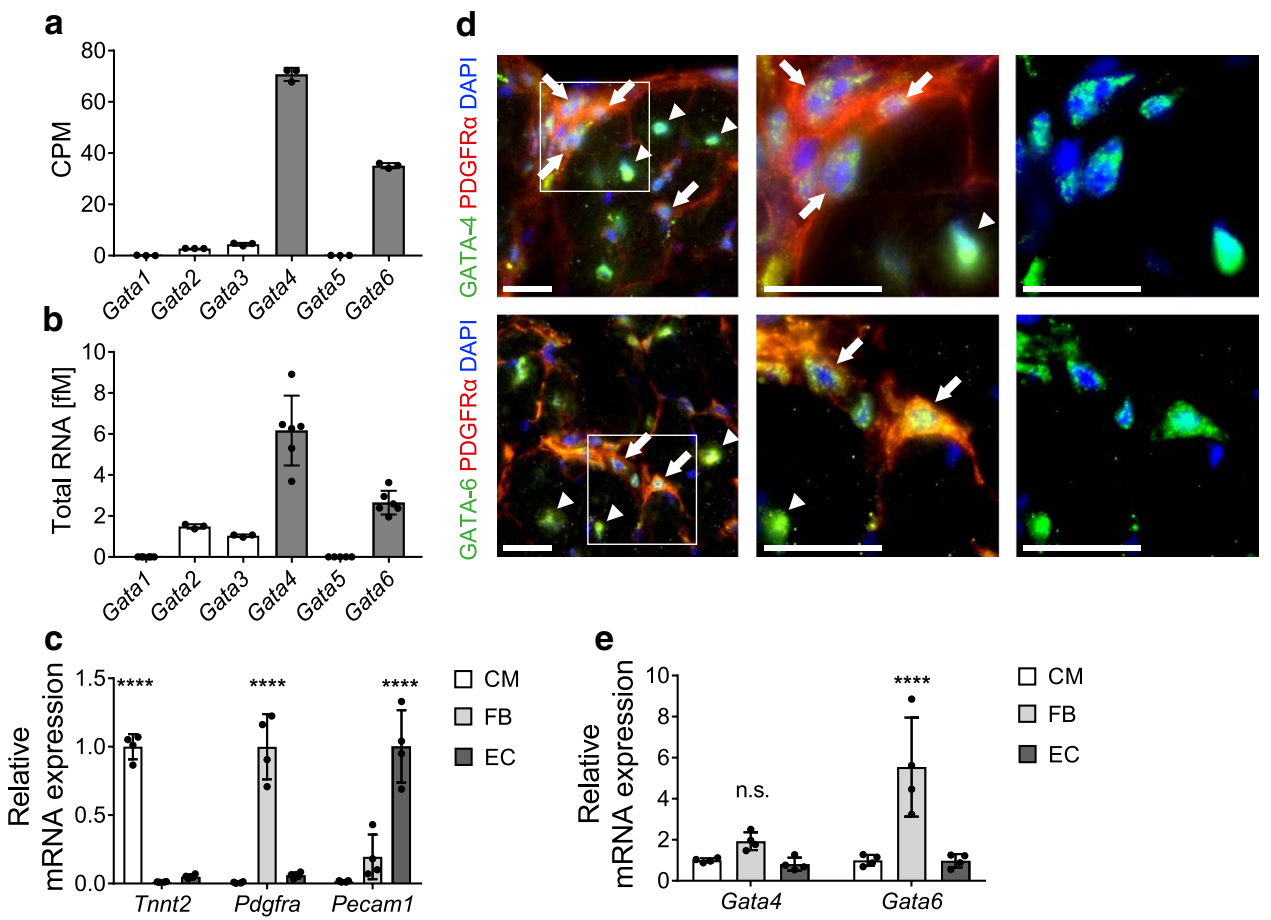

Fig. 1 Gata4 and Gata6 show the highest expression among GATA family members in cardiac fibroblasts. a, b Quantification of Gatafactor RNA expression levels in isolated cardiac fibroblasts from RNA-sequencing [shown as counts per million reads (CPM, a)] and quantitative real-time-PCR (b) demonstrates that Gata4 and Gata6 are the highest expressed GATA family transcription factors in cardiac fibroblasts. RNA expression levels are normalized to Rpl7 (b). c Quantitative real-time-PCR of cell-type specific marker genes shows high purity of isolated cardiomyocytes (CM), fibroblasts (FB) and endothelial cells (EC) from adult mouse hearts. d Representative immunofluorescence images from transverse mouse heart sections show GATA-4 (upper images, green) and GATA-6 (lower images, green) in cardiac fibroblasts (stained with PDGFR $\alpha$, red), nuclei are stained with DAPI (blue). Arrows indicate GATA-4 or GATA-6 positive cardiac fibroblasts, arrowheads indicate GATA-4 or GATA-6 positive cardiomyocytes. Scale bar $20 \mu \mathrm{m}$. e Quantitative real-time-PCR shows RNA expression level of Gata4 and Gata6 in FB compared to CM and EC. RNA expression levels are normalized to Gapdh (c, e). Data are shown as mean \pm SD. Two-way ANOVA with Sidak's multiple-comparisons test was used to test for significant differences. n.s. indicates no statistical significance between groups, $* * * * p<0.0001$ 


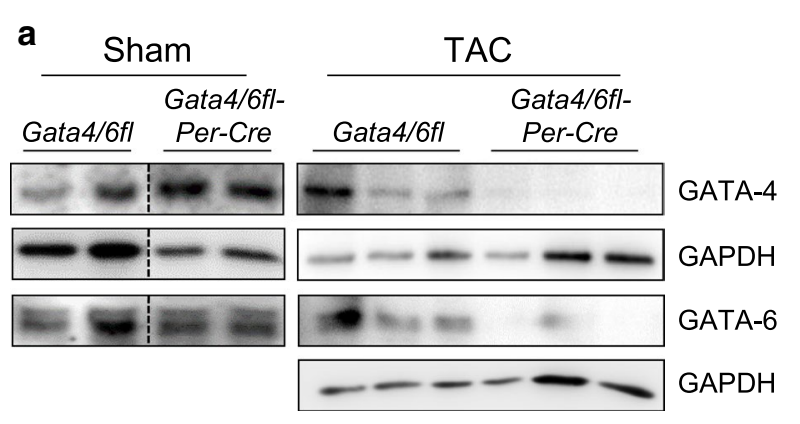

b

Sham

TAC

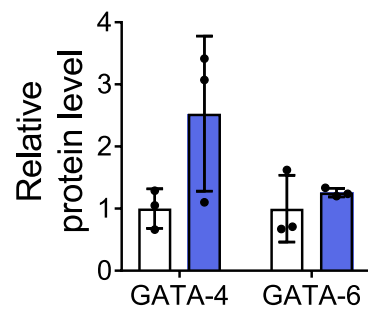

Gata4/6fl

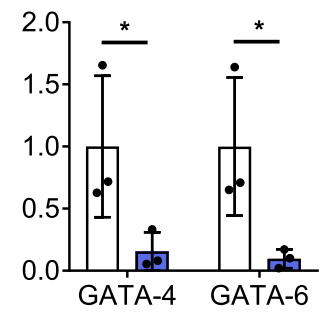

Gata4/6fl-
Per-Cre

C
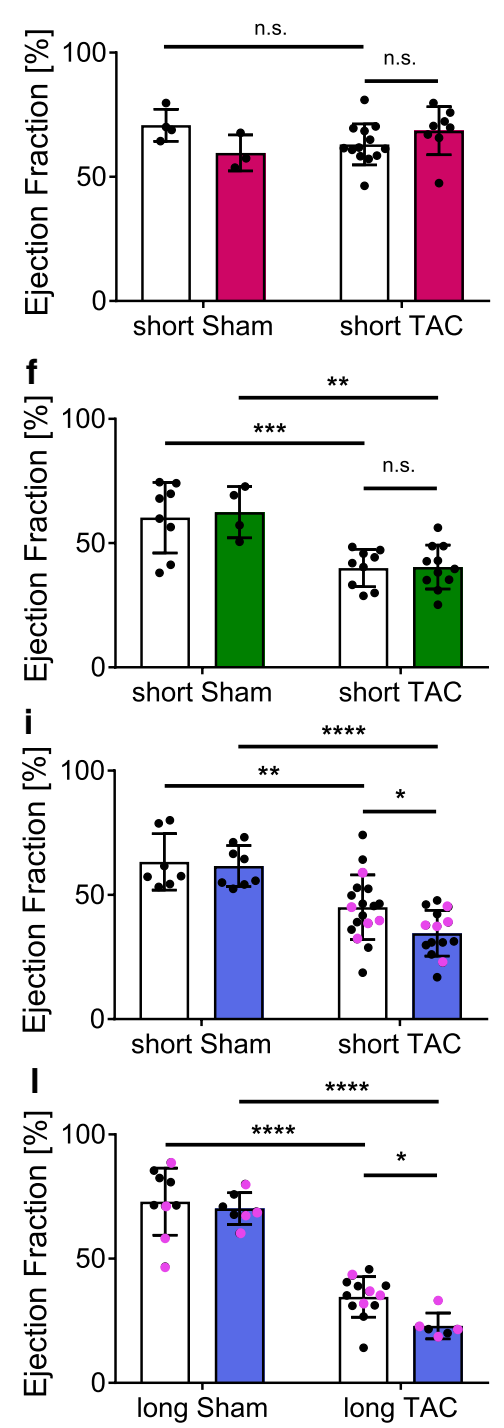

d
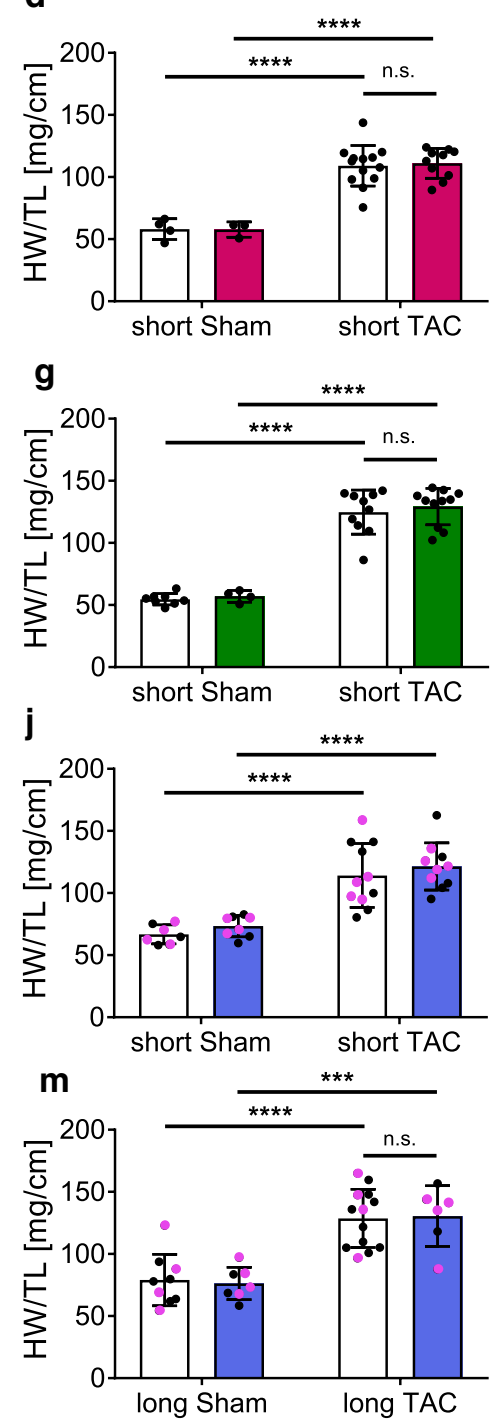

e

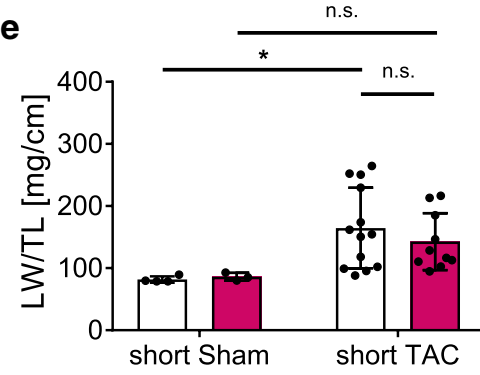

h
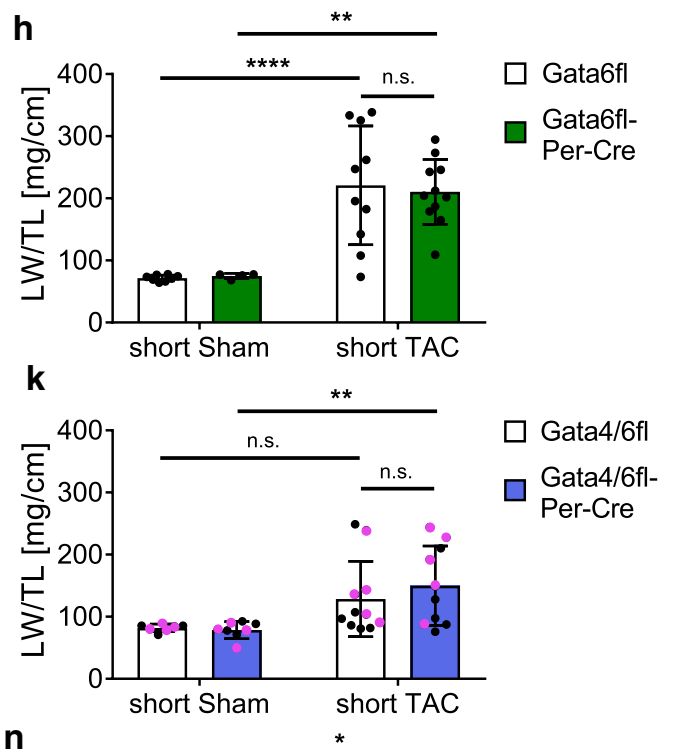

n

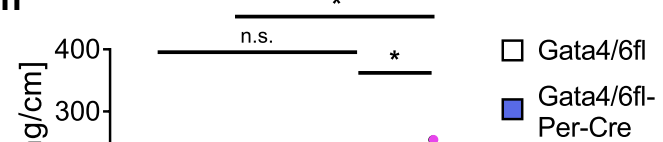

wild-type cardiac fibroblasts showed 16-fold higher counts of Gata4 and eightfold higher counts of Gata6 per million reads compared to Gata3, which showed the third highest expression level (Fig. 1a). In a second approach, we analyzed the absolute expression level of each GATA factor by quantitative real-time PCR (qPCR) from isolated heart fibroblasts. We found a similar expression pattern as revealed by RNA sequencing, with the highest expression level for Gata4 (around $6 \mathrm{fM}$ ) and Gata6 (around $3 \mathrm{fM}$ ), significantly lower RNA amounts of Gata2 and Gata3 (below $2 \mathrm{fM}$ ), and negligible amounts of Gatal and Gata5 (Fig. 1b). Evaluation of cell purity showed high enrichment of cell-type specific marker genes in fractions of isolated adult cardiomyocytes (CM), fibroblasts (FB), and endothelial cells (EC), 
4Fig. 2 Combined deletion of Gata4 and Gata6 in activated cardiac fibroblasts aggravates heart failure after short- and long-term pressure overload. a, b Western blot of isolated cardiac fibroblasts from Gata4/6fl-Per-Cre and Gata4/6 $f$ littermate control mice after pressure overload or sham (a) and quantification of relative protein levels normalized to GAPDH (b) showing efficient reduction of GATA-4 and GATA-6 protein levels after TAC in Gata4/6fl-Per-Cre mice. c-e Quantification of the ejection fraction (c), heart weight/tibia length ratio (HW/TL, d) and lung weight/tibia length ratio (LW/TL, e) in Gata4fl-Per-Cre and Gata4fl littermate control mice shows signs of compensated cardiac hypertrophy without significant differences in both groups after short-term pressure overload. f-h Quantification of the ejection fraction (f), HW/TL $(\mathbf{g})$, and LW/TL ratio (h) in Gata6fl-Per-Cre and Gata6fl littermate control mice shows decreased cardiac function without significant differences in both groups after short-term pressure overload. i-n Quantification of the ejection fraction $(\mathbf{i}, \mathbf{l}), \mathrm{HW} / \mathrm{TL}(\mathbf{j}, \mathbf{m})$, and LW/TL ratio $(\mathbf{k}, \mathbf{n})$ in Gata4/6fl-PerCre mice and Gata4/6fl littermate controls shows that mice with deletion of Gata4 and Gata6 in cardiac fibroblasts display a significantly worse cardiac function after short- and long-term pressure overload and an increased LW/TL ratio after long-term pressure overload compared to littermate control mice, while the HW/TL ratio is not significantly different. Selected animals for further histological analysis (see Fig. 3) are indicated in pink. Data are shown as mean \pm SD. Twoway ANOVA with Sidak's multiple-comparisons test was used to test for statistical significance. n.s. indicates no statistical significance between groups. ${ }^{*} p<0.05, * * p<0.01, * * * p<0.001, * * * * p<0.0001$

indicating that the described Gata factor expression level are indeed resulting from cardiac fibroblasts (Fig. 1c). Immunofluorescence co-staining for GATA-4 or GATA- 6 and platelet-derived growth factor receptor alpha (PDGFR $\alpha$ ), which serves as a marker for fibroblasts in cardiac tissue, confirms the localization of GATA-4 and GATA- 6 in the nuclei of cardiac fibroblasts (Fig. 1d) in transverse mouse heart sections. Moreover, GATA-4 and GATA-6 staining also showed a strong signal in the nuclei of large PDGFR $\alpha$-negative cells, which are most likely cardiomyocytes. In addition, comparison of the Gata4 and Gata6 mRNA expression levels in isolated cell fractions indicated fibroblasts to express at least equal Gata4 levels, and even significantly higher Gata6 levels compared to cardiomyocytes and endothelial cells (Fig. 1e).

\section{Deletion of Gata4 and Gata6 in activated cardiac fibroblasts aggravates heart failure after pressure overload}

To investigate the functional relevance of Gata4 and Gata6 in activated fibroblasts in vivo, we interbred Gata $4^{f l o x} f f o x$ and

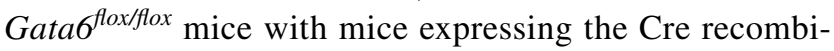
nase linked to a partial periostin (Postn) promoter to obtain single deletion of Gata4 (Postn ${ }^{\text {Crel+}}$; Gata4 ${ }^{f l o x}$ flox , short: Gata4fl-Per-Cre, Suppl Figure 1a pink) and Gata6 (Post$n^{\text {Cre/+}}$; Gata6 ${ }^{f l o x / f l o x}$, short: Gata6fl-Per-Cre, Suppl. Figure 1a green), as well as combined deletion of Gata4/6 (Postn ${ }^{\mathrm{Cre} /+}$; Gata4 $^{\text {floxfflox }}$; Gata6 ${ }^{\text {floxfflox }}$, short: Gata4/6fl-Per-Cre, Suppl. Figure 1a blue) in activated cardiac fibroblasts [23, 37, 48].
The Per-Cre mice were previously described as an efficient model to target gene expression in adult activated fibroblasts following cardiac injury, while quiescent fibroblasts or cardiomyocytes of the heart are predominantly unaffected $[5,16$, 20, 21, 34, 39]. Immunoblot analysis of isolated fibroblasts from stressed hearts of Gata4/6fl-Per-Cre mice showed a marked reduction of over $80 \%$ for GATA- 4 and over $90 \%$ for GATA-6 protein levels after pressure overload compared to littermate control mice (Fig. 2a, b), while total GATA-4 and GATA-6 levels in isolated fibroblasts of sham mice or whole heart tissue of these mice were not significantly affected (Fig. 2a, b and Suppl. Figure 1b). RNA levels of Gata4 and Gata6 in isolated fibroblasts from wild-type mice were unchanged after pressure overload compared to sham samples (Suppl. Figure 1c). Measurements of the heart weight/ tibia length (HW/TL) and lung weight/tibia length (LW/ TL) ratios of the Gata4fl-Per-Cre and Gata6fl-Per-Cre mice showed a marked increase in both groups after short-term ( 2 weeks) pressure overload by transverse aortic constriction (TAC), demonstrating a significant hypertrophic response of the heart with signs of pulmonary congestion (Fig. 2d, e, g, h). Assessment of cardiac function by transthoracic echocardiography showed no significant differences of the cardiac ejection fraction (EF) in Gata4fl-Per-Cre mice after shortterm sham or TAC surgery compared to littermate control mice, indicating a sufficient compensation of the pressure overload in both groups (Fig. 2c, additional echocardiography parameters in Suppl. Table 2). The Gata6fl-Per-Cre mice showed a significantly decreased EF after short-term pressure overload compared to sham mice, but as the cardiac function of littermate control mice equally decreased after TAC, we found that single deletion of Gata6 in cardiac fibroblasts is not sufficient to affect the cardiac function after pressure overload (Fig. 2f). Analysis of cardiac function, HW/TL and LW/TL ratios in Wt-Per-Cre mice did not reveal any significant influence of the Per-Cre in sham mice or after pressure overload (Suppl. Figure 1d-f). As previous studies demonstrated that GATA-4 and GATA- 6 exert partially redundant functions in cardiomyocytes in case of single deletion of one of these factors, we next investigated the morphological and functional effects of a double deletion of Gata4 and Gata6 in activated cardiac fibroblasts [44, 51]. After short-term TAC, we found equally increased HW/TL and LW/TL ratios in Gata4/6f-Per-Cre and littermate control mice compared to sham animals (Fig. 2j, k). However, the cardiac function of mice with Gata4/6-double deletion was significantly worse compared to littermate control mice after short-term pressure overload (Fig. 2i). This effect was maintained after prolonged exposure to pressure overload for 6 weeks (long-term) when cardiac function was further decreased in Gata4/6fl-Per-Cre and littermate control mice compared to the short time point, but remained significantly worse in Gata4/6fl-Per-Cre versus control animals (Fig. 2l). 

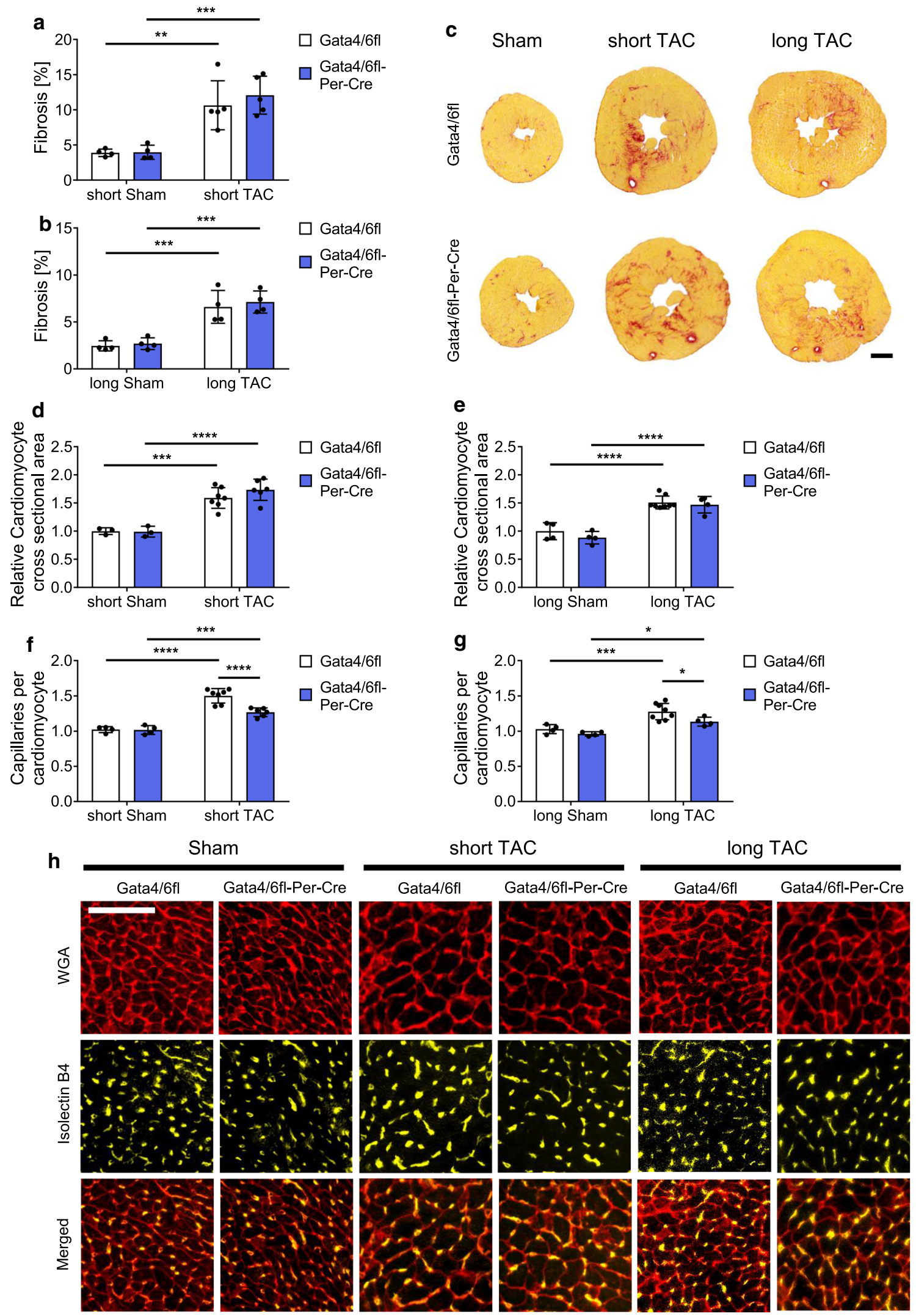
4Fig. 3 Mice with fibroblast-specific deletion of Gata4 and Gata6 show a reduced capillary density after pressure overload. a-c Quantification of cardiac fibrosis from transverse mouse heart sections stained with Sirius-red after short (a) and long (b) pressure overload and representative pictures of Sirius-red stained hearts (c), scale bar $1 \mathrm{~mm}$. d, e Quantification of the cardiomyocyte cross-sectional area after short (d) and long (e) pressure overload. f-h Quantification of the capillary density displayed as capillary per cardiomyocyte ratio after short (f) and long (g) pressure overload and representative pictures of WGA and IsolectinB4 stained heart sections (h), scale bar $50 \mu \mathrm{m}$. Data are shown as mean \pm SD. Two-way ANOVA with Sidak's multiple-comparisons test was used to test for statistical significance. $* p<0.05, * * p<0.01, * * * p<0.001, * * * * p<0.0001$

The HW/TL ratio was similarly increased in Gata4/6fl-PerCre mice and controls, while the LW/TL ratio was only increased in the Gata4/6f-Per-Cre mice, but not in the littermate controls in this cohort, indicating aggravated pulmonary congestion due to cardiac dysfunction as consequence of reduced GATA- 4 and GATA- 6 levels in cardiac fibroblasts (Fig. 2m, n). Furthermore, qPCR analysis of a panel of fibrosis and cardiac embryonic genes revealed an increased mRNA expression of Nppa (ANP) in the myocardium of Gata $4 / 6 \mathrm{fl}$-Per-Cre versus control mice after long $\mathrm{TAC}$, again as sign of aggravated heart failure in these mice (Suppl. Figure 1g).

Overall, we found that single deletion of Gata4 or Gata6 in activated cardiac fibroblasts did not significantly affect the cardiac response to pressure overload, while mice with double deletion of Gata4/6 displayed a reduced cardiac function after short- and long-term, and more pulmonary congestion after long-term TAC compared to littermate controls. Therefore, our further analyses predominantly focus on Gata4/6 double deletion rather than single deletion of Gata4 or Gata6.

\section{Deletion of Gata4/6 in cardiac fibroblasts reduces the capillary density in the heart after pressure overload}

To investigate myocardial structural changes upon fibroblast Gata4/6 deletion, we used Sirius-red staining to detect fibrosis in response to short- or long-term pressure overload (mice that were selected for histological analysis are indicated in Fig. $2 \mathrm{i}-\mathrm{n}$ as pink datapoints). The fibrotic area significantly increased in Gata4/6fl-Per-Cre and control mice following short- and long-term TAC versus sham operated mice, but no differences were observed between both genotypes (Fig. 3a-c). Additional quantification of the perivascular fibrosis ratio (PFR) showed a similar increase of the PFR after short and long-term TAC compared to sham, while we did not observe any difference between Gata4/6fl-Per-Cre and control mice (Suppl. Figure 2a, b). We also quantified the number of fibroblasts per cardiomyocyte to detect potential differences in fibroblast cell numbers due to changes in developmental differentiation or proliferation. While the number of fibroblasts per cardiomyocyte significantly increased in response to short- and long-term pressure overload, we did not find significant changes between Gata4/6flPer-Cre and control mice (Suppl. Figure 2c). Furthermore, immunofluorescence staining for the leukocyte marker CD45 did not reveal any differences in the number of inflammatory cells between Gata4/6fl-Per-Cre and control mice (Suppl. Figure 2d). Moreover, quantification of $\alpha$-smooth muscle actin positive vessels from immunofluorescence stainings did not indicate any impact of Per-Cre driven Gata4/6 deletion on the amount of cardiac arterioles and arteries (Suppl. Figure 2e, f). Next, we determined the hypertrophic response and capillarization of cardiac tissue after staining for wheat germ agglutinin (WGA) and Isolectin B4 (IB4). As expected, the cardiomyocytes significantly increased in size in response to pressure overload as shown in Fig. 3d, e. Nevertheless, the cardiomyocyte cross-sectional area similarly increased in Gata4/6f-Per-Cre and control mice, indicating that the cellular mechanisms enabling compensatory cardiac hypertrophy do not depend on the expression levels of Gata4 and Gata6 in cardiac fibroblasts. Quantification of the fibrotic area and the hypertrophic response in Gata4 and Gata6 single deleted mice and Wt-Per-Cre mice showed a similar increase after TAC compared to sham, while no differences occurred between the Gata4 or Gata6 single deletion or control mice (Suppl. Figure 3a-f). In contrast to the unaffected fibrotic and hypertrophic responses, we found that the increase in the number of capillaries per cardiomyocyte after short- and long-term TAC compared to sham was significantly reduced in Gata4/6fl-Per-Cre compared to control mice (Fig. 3f-h). Capillary density was unchanged in fibroblast Gata4 single deleted mice or Wt-Per-Cre mice after TAC, or even increased in the Gata6 single deleted mice (Suppl. Figure 3g-i). Sham operated Gata4/6fl-PerCre mice also showed no reduction in cardiac capillarization versus Gata4/6fl mice, because Cre activation and, therefore, Gata4/6 deletion does only occur after TAC surgery in our model. Differences of the angiogenic response in control mice between the analyzed groups after TAC are most likely due to slight variation in the genetic mouse background, therefore, only littermate animals were used as respective controls for each group. The impaired angiogenic response upon combined Gata $4 / 6$ deletion after TAC raised the question, how the deletion of the transcription factors Gata4 and Gata6 in cardiac fibroblasts could affect the formation of cardiac endothelial cells, which were not directly targeted in our in vivo model. 


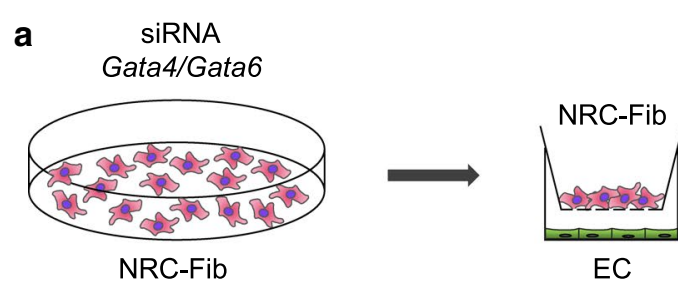

b

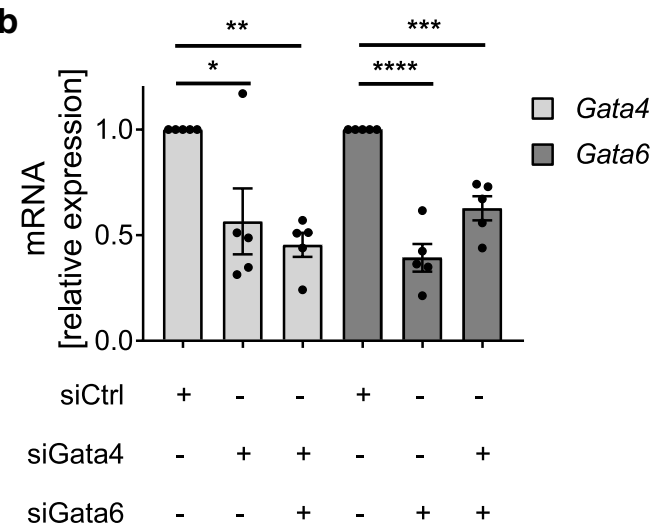$$
\text { c }
$$

e
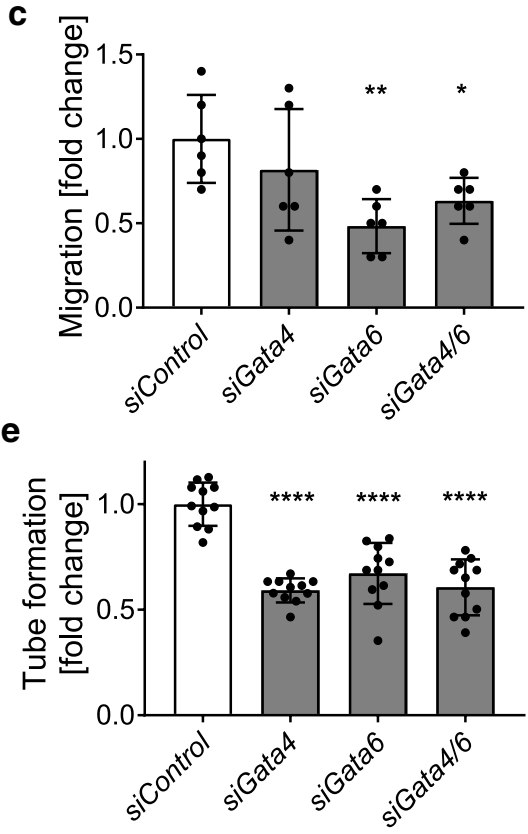

g
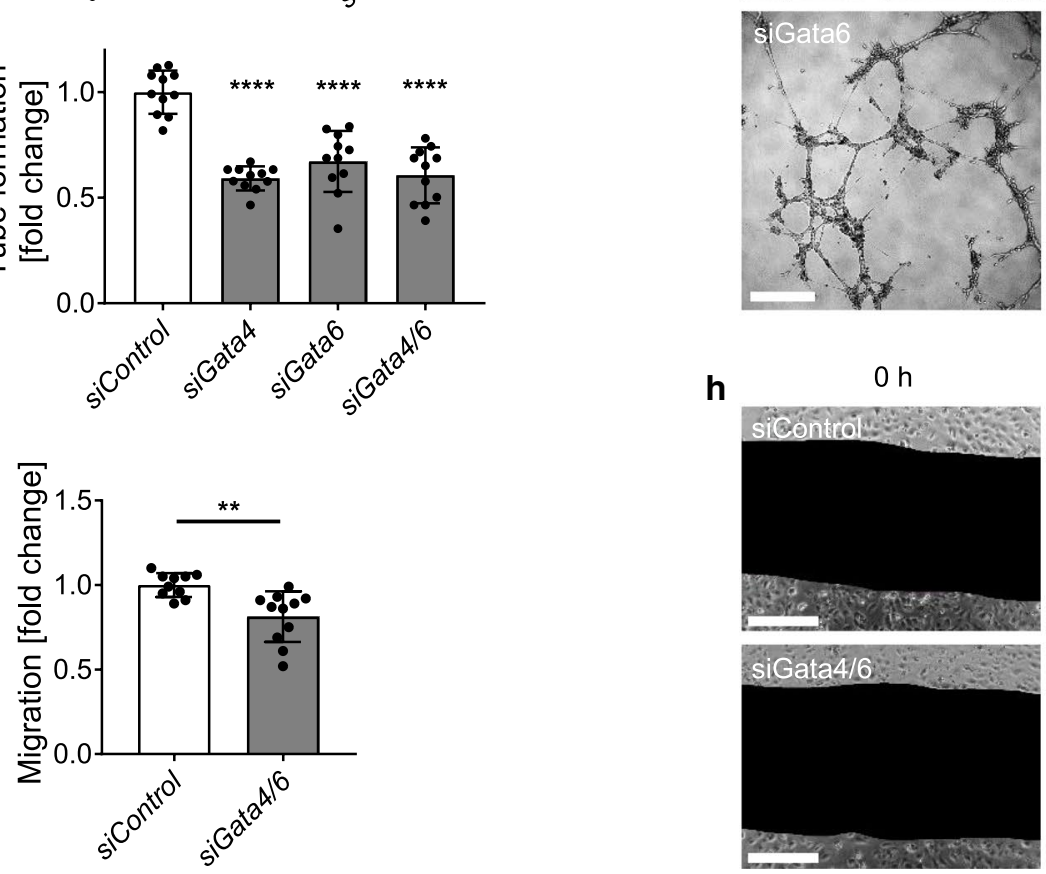

d

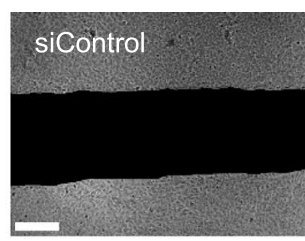

$6 \mathrm{~h}$

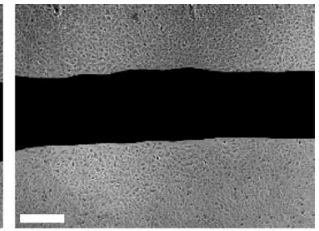

\section{siGata4}
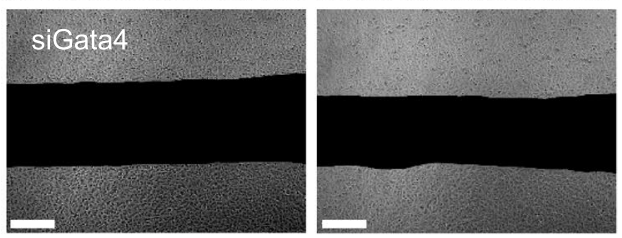

\section{sigatab}


h

$\mathrm{Oh}$
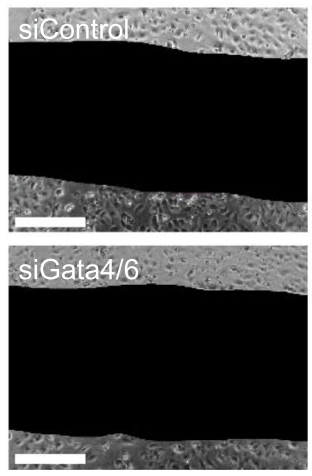
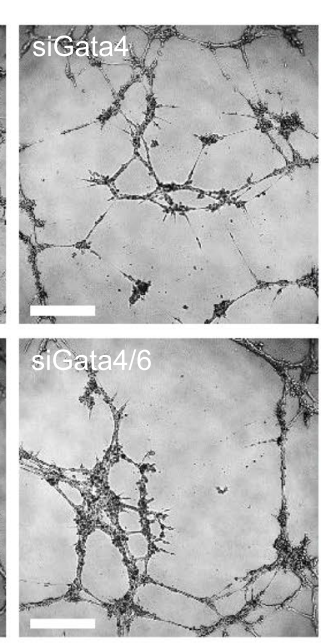

$10 \mathrm{~h}$
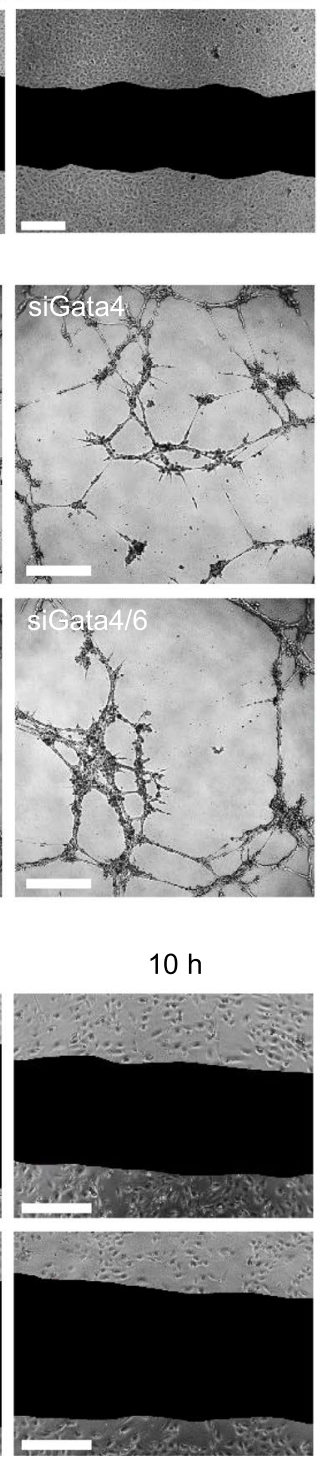
४Fig. 4 Endothelial cells exert reduced migration and tube formation in co-culture with fibroblasts treated with siRNA to downregulate Gata 4 and Gata6 compared to control-treated fibroblasts. a Schematic overview of co-culture experimental setup. Gata4 and Gata6 were downregulated in neonatal rat cardiac fibroblasts (NRC-Fib) by siRNA transfection $48 \mathrm{~h}$ before co-culture with HUVEC or HCMEC. b Relative mRNA level of Gata4 and Gata6 in rat cardiac fibroblasts $48 \mathrm{~h}$ after siRNA transfection. RNA expression levels are normalized to Gapdh. c, d Quantification of endothelial cell (HUVEC) migration (c) and representative images (d) from scratch assays. Pictures were taken directly after scratch $(0 \mathrm{~h})$ and $6 \mathrm{~h}$ later. e, f Quantification of tube formation (e) and representative pictures (f) of HUVEC/Fibroblast co-cultures on a 3D matrigel matrix. Images for quantification of tube formation were taken after $8 \mathrm{~h}$ of co-culture. Quantification of cardiac microvascular endothelial cell (HCMEC) migration (g) and representative images $(\mathbf{h})$. Pictures were taken directly after scratch $(0 \mathrm{~h})$ and $10 \mathrm{~h}$ later. Scale bar $(\mathbf{d}, \mathbf{f}, \mathbf{h}) 200 \mu \mathrm{m}$. Data are shown as mean \pm SD. One-way ANOVA with Dunnett's multiple-comparisons test $(\mathbf{b}, \mathbf{c}, \mathbf{e})$ or unpaired $t$ test $(\mathbf{g})$ was used to test for statistical significance. $* p<0.05, * * p<0.01, * * * p<0.001, * * * * p<0.0001$

\section{In vitro co-culture of Gata4/6-deprived cardiac fibroblasts and endothelial cells shows reduced endothelial cell migration and tube formation}

To address the finding that fibroblast-specific double-deletion of Gata4 and Gata6 reduces the angiogenic response in the heart after pressure overload, we established an in vitro co-culture system. Therefore, cardiac fibroblasts from newborn rats (1-3 days-old) were isolated and transfected with specific siRNAs to downregulate the expression of Gata4, Gata6 or both. These targeted fibroblasts or control cells were cultured in permeable inserts on top of endothelial cells, allowing the exchange of soluble factors by diffusion in the culture medium (Fig. 4a). Due to the distance between the fibroblast covered inserts and the bottom of the cell culture dish below, direct cell-cell contact of fibroblasts and endothelial cells was prevented. Quantification of the mRNA expression level of Gata4 and Gata6 and protein level of GATA- 4 and GATA- 6 in cardiac fibroblasts after siRNA transfection demonstrated a downregulation of around 50\% on RNA and protein level compared to fibroblasts transfected with siRNA control (Fig. 4b and Suppl. Figure 3j, $\mathrm{k})$. The endothelial cells (HUVEC) showed a markedly reduced migration after $6 \mathrm{~h}$ of co-culture with siGata6 or siGata $4 / 6$ treated fibroblasts compared to controls, while coculture with siGata4 treated fibroblasts did not significantly affect the HUVEC migration (Fig. 4c, d). Another important parameter of endothelial activity is the ability to form a closed interaction network on matrigel matrix, which can be assessed in a tube formation assay. HUVECs that were co-cultured with siGata4, siGata6 or siGata4/6 transfected fibroblasts on matrigel built significantly less closed tubestructures compared to controls (Fig. 4e, f). To confirm the anti-angiogenic effect of Gata4/6 deletion in fibroblasts on microvascular cells, we additionally conducted co-culture experiments with human cardiac microvascular endothelial cells (HCMEC) and siGata4/6 or control treated fibroblasts. The HCMECs showed a significantly reduced migration after $10 \mathrm{~h}$ of co-culture with siGata $4 / 6$ treated fibroblasts compared to controls (Fig. 4g, h). In conclusion, our in vitro experiments support the finding that fibroblast Gata4/6 is required for an adaptive expansion of endothelial cells and that this intercellular crosstalk is presumably mediated by soluble factors secreted from cardiac fibroblasts.

\section{Simultaneous deletion of Gata4/6 in cardiac fibroblasts changes the transcriptome towards higher expression of anti-angiogenic mediators}

To identify target genes of Gata $4 / 6$ in cardiac fibroblasts that might influence the adaptive angiogenic response in the heart after pressure overload, we isolated fibroblasts from hearts of the previously described Gata4fl, Gata6fl, and Gata4/6 $f$ as well as from wild-type mice. The isolated fibroblasts were cultured in vitro and subsequently the loxP targeted exons of the Gata4 (exon 3-5) and the Gata6 gene (exon 2) were deleted by adenoviral delivery of the Cre recombinase (AdCre). Fibroblasts from Gata6fl mouse hearts were infected with $\beta$-galactosidase expressing adenovirus (Ad $\beta \mathrm{Gal}$ ) and used as control samples. Wild-type cardiac fibroblasts infected with AdCre served as additional controls. The genome-wide transcriptome was analyzed using bulk RNA-sequencing and differentially expressed (DE) genes between the groups (at least twofold up or downregulation in Gata4/6 deletion compared to control, and $p<0.05$ ) are shown in the heatmap (Fig. 5a). Compared to Gata6flAd $\beta$ Gal control samples, we found 3720 DE genes in fibroblasts with Gata4 deletion, 667 DE genes upon Gata6 deletion and $3154 \mathrm{DE}$ genes in fibroblasts with Gata4/6 double deletion. Visualization of upregulated genes upon Gata4/6 single or double deletion in a Venn diagram showed that $60 \%$ of the upregulated genes in the Gata4/6 double deleted cells were also upregulated in Gata4 single deletion, while only $17 \%$ were upregulated in samples with Gata6 single deletion (Fig. 5b). Because we did not observe any phenotype in mice with Gata4 or Gata6 single deletion in fibroblasts, we focused the analysis on the samples with Gata4/6 double-deletion. In this group, we found 1408 upregulated genes which belonged to the GO (biological process) clusters blood vessel development, tissue morphogenesis and negative regulation of cell proliferation (Fig. 5a, Suppl. Figure 4a). Highly upregulated example genes in these clusters include angiogenic inhibitors (Angpt4, Cnmd, Thbs 1), modulators of tissue morphogenesis (Agt, Adamts12), and cell receptors with anti-angiogenic effects $(C d 36, F l t 1$, other example genes are listed in Fig. 5a). The expression levels of selected upregulated genes detected in the RNA-sequencing 

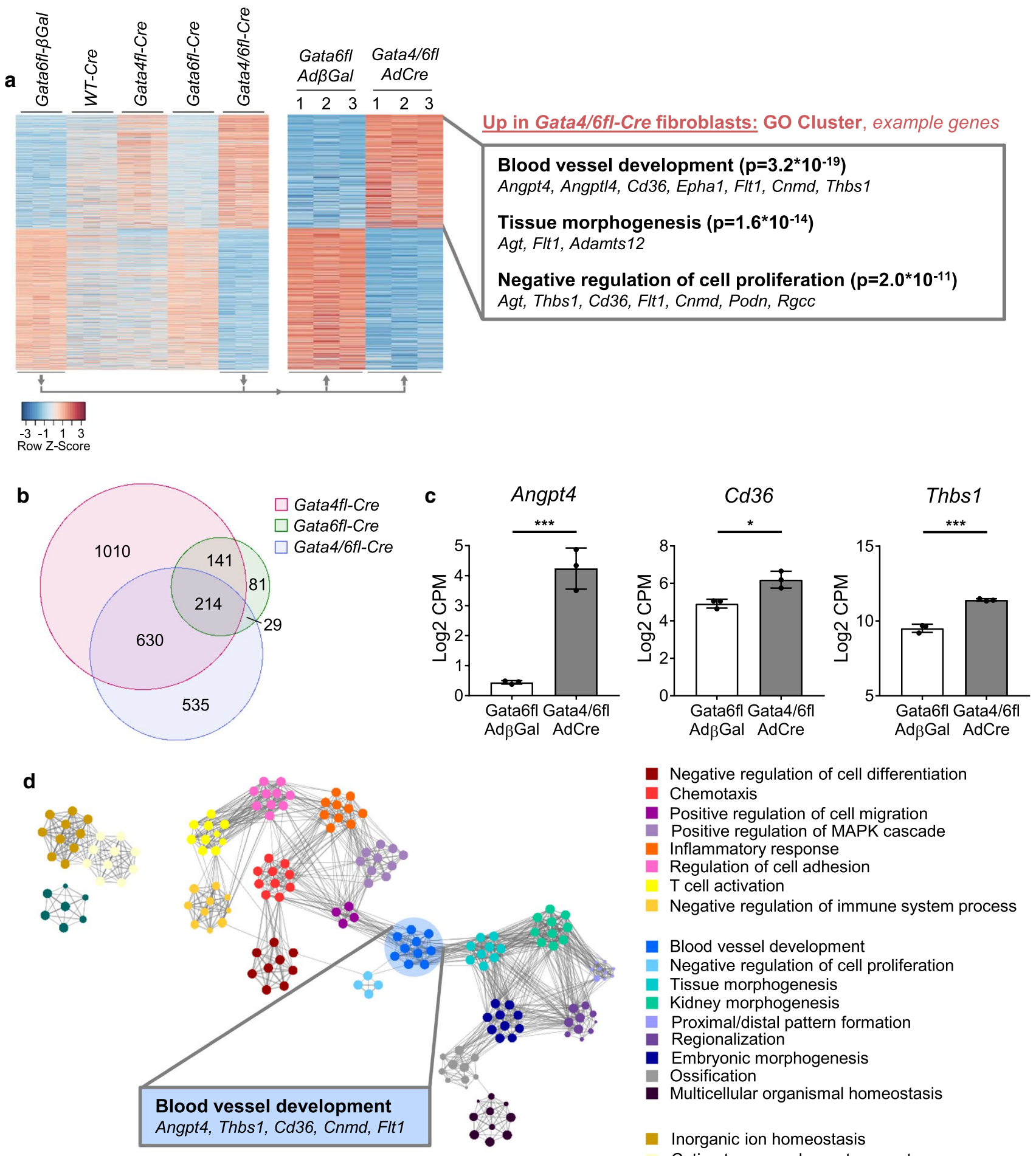
Negative regulation of cell differentiation Chemotaxis
Positive regulation of cell migration
Positive regulation of MAPK cascade
Inflammatory response
Regulation of cell adhesion
$T$ cell activation
Negative regulation of immune system process
Blood vessel development
Negative regulation of cell proliferation
Tissue morphogenesis
Kidney morphogenesis
Proximal/distal pattern formation
Regionalization
Embryonic morphogenesis
Ossification
Multicellular organismal homeostasis
Inorganic ion homeostasis
Cation transmembrane transport
- Organ hydroxy compound transport

Fig. 5 Transcriptome analysis of isolated cardiac fibroblasts showing an upregulation of anti-angiogenic genes in cells with Gata4/Gata6 deletion compared to control cells. a Heatmap of differentially regulated genes showing all analyzed groups (left panel) and direct comparison of Gata6fl- $\beta \mathrm{Gal}$ (control) vs. Gata4/6fl-Cre (right panel) isolated cardiac fibroblast samples ( $n=3$ in each group). Gene ontology (GO, biological process) classification and selected example genes are demonstrated on the right. Bioinformatic analysis of RNA-Seq data is described in the "Materials and methods" section. b Venn diagram of significantly upregulated genes in fibroblasts with Gata4, Gata6, and Gata4/6 deletion compared to Gata6fl- $\beta$ Gal control samples. c RNA expression level of selected anti-angiogenic genes from RNA-sequencing. d Visualization of the top 20 GO BP clusters and relationships as a network plot. Each node represents an enriched term and is colored depending on its cluster ID, the cluster ID legend is shown on the right. Terms with a similarity $>0.3$ are connected by edges. Data are shown as mean \pm SD. Student's $t$ test was used for comparison of two groups. $* p<0.05, * * * p<0.001$ 
are shown in Fig. 5c. 1746 genes were downregulated in Gata4/6 double-deleted fibroblasts compared to control cells and mainly belonged to the GO clusters virus response or interferon-beta response, for example Cxcl10, Stat1, and Irf7 (Suppl. Figure 4b). Visualization of the gene clusters in a GO network shows the cluster inter-relation based on similarity (Fig. 5d), where the gene set annotated in the "blood vessel development" cluster (medium blue) shows high similarity (indicated by the number of connecting edges) with the gene sets of the clusters "positive regulation of cell migration" (left, purple) and "tissue morphogenesis" (right, lighter blue).

We subsequently focused on the upregulated genes annotated in blood vessel development and selected genes with a functional annotation in negative regulation of angiogenesis. Ranking of the 11 genes annotated in this functional class identified Angpt4 and Thbs 1 as the two candidates meeting the following two selection criteria: highly different expression levels compared to control samples and high total expression levels in the Gata4/6 double-deletion samples. The encoded proteins angiopoietin-4 (ANGPT4) and thrombospondin-1 (THBS1) are characterized as secreted factors, which enables anti-angiogenic effects without direct contact of the producing fibroblasts to the targeted endothelial cells, similar to the effect we observed in the co-culture system upon Gata4/6 deletion in fibroblasts. Interestingly, the gene encoding the THBS1 receptor platelet glycoprotein 4 (Cd36) was also significantly upregulated in fibroblasts upon Gata4/6 double-deletion, while single deletion of Gata4 or Gata6 caused lower changes in the expression level (upregulation Gata4/6-deletion 149\%, Gata4-deletion 62\%, Gata6-deletion 36\% vs. control). Although CD36 mediates a variety of ligand and cell-type specific effects, a mechanistic link how elevated $C d 36$ RNA expression level in fibroblasts might exert an anti-angiogenic effect on cardiac endothelial cells is so far undescribed. It is, however, well known that components of the extracellular matrix serve as ligands for the CD36 receptor [40].

\section{Deposition of the main extracellular matrix components is not affected by deletion of Gata4 and Gata6 in cardiac fibroblasts}

Following cardiac injury, activated cardiac fibroblasts are the main contributors to the deposition of extracellular matrix (ECM), which increases cardiac stiffness and thereby reduces the systolic and diastolic function of the heart. Although overall quantification of collagen deposition did not reveal quantitative differences in Sirius-red stained hearts of Gata4/6fl-Per-Cre and control mice after TAC, we sought to identify potential changes in the extracellular matrix composition that might affect cardiac function. Therefore, we isolated the extracellular matrix from whole hearts of Gata4/6fl-Per-Cre and Gata4/6fl control mice after short-term pressure overload and analyzed the proteins deposited in the extracellular matrix by mass spectrometry (Fig. 6a). Analysis of the primary components showed an overall similar composition of extracellular matrix proteins in mice with Gata4/6 double deletion and controls (Fig. 6b). Further exploration of the main ECM proteins displayed no major difference in protein abundancies, especially for collagens, glycoproteins, and proteoglycans (Fig. 6d and Suppl. Table 3 ). We found only 28 proteins with significantly different levels in the ECM of Gata4/6 double deletion and control hearts (Fig. 6c and Suppl. Table 4). Among them, the protein levels of the THBS1 receptor CD36 were the most significantly changed with no detectable deposition in control ECM and a mean of 2.3 normalized counts in the ECM of Gata4/6f-Per-Cre hearts (Fig. 6c, e). CD36 is a transmembrane glycoprotein that can be secreted from cells, and that is expressed in various cell types, including (cardiac) fibroblasts, endothelial cells and macrophages [6, 14, $31,46]$. It functions to facilitate cellular long-chain fatty acid uptake, but also mediates anti-angiogenic signaling [10, 18]. Beside the marked change in CD36 abundance, the overall result of the ECM analysis did not indicate major changes in the ECM composition between Gata4/6fl-Per-Cre and control mice that would directly affect cardiac function. Therefore, we concluded that the reduced cardiac capillarization of Gata4/6fl-Per-Cre mice in response to pressure overload constitutes the key mechanism causing the deteriorated cardiac function compared to control animals.

\section{Increased secretion of angiogenic inhibitors ANGPT4 and THBS1 from Gata4/6-deleted cardiac fibroblasts mediates reduced angiogenesis}

To directly investigate the effects of secreted ANGPT4 or THBS 1 on endothelial angiogenic function, we treated HUVECs with recombinant proteins. As expected, we observed reduced migration and tube formation in ANGPT4 or THBS1 treated cells compared to controls (Fig. 7a-d). To prove the relevance of the anti-angiogenic effect at endogenous protein concentrations, we again conducted co-culture experiments with siRNA transfected cardiac fibroblasts and HUVECs. As described before, Gata4 and Gata6 were simultaneously downregulated in cardiac fibroblasts, which caused significantly increased mRNA expression of Angpt4 and Thbs 1 in cardiac fibroblasts, while expression levels of the angiogenic factor Vegfa that was previously described as target gene of Gata4 in cardiomyocytes, was not significantly changed (Fig. 7e) [12]. Downregulation of Gata4 and Gata6 resulted in significantly reduced cell migration and tube formation of co-cultured HUVECs (Fig. 7f-i). Additional deletion of Angpt4 in cardiac fibroblasts restored endothelial migration and tube formation almost to the level 

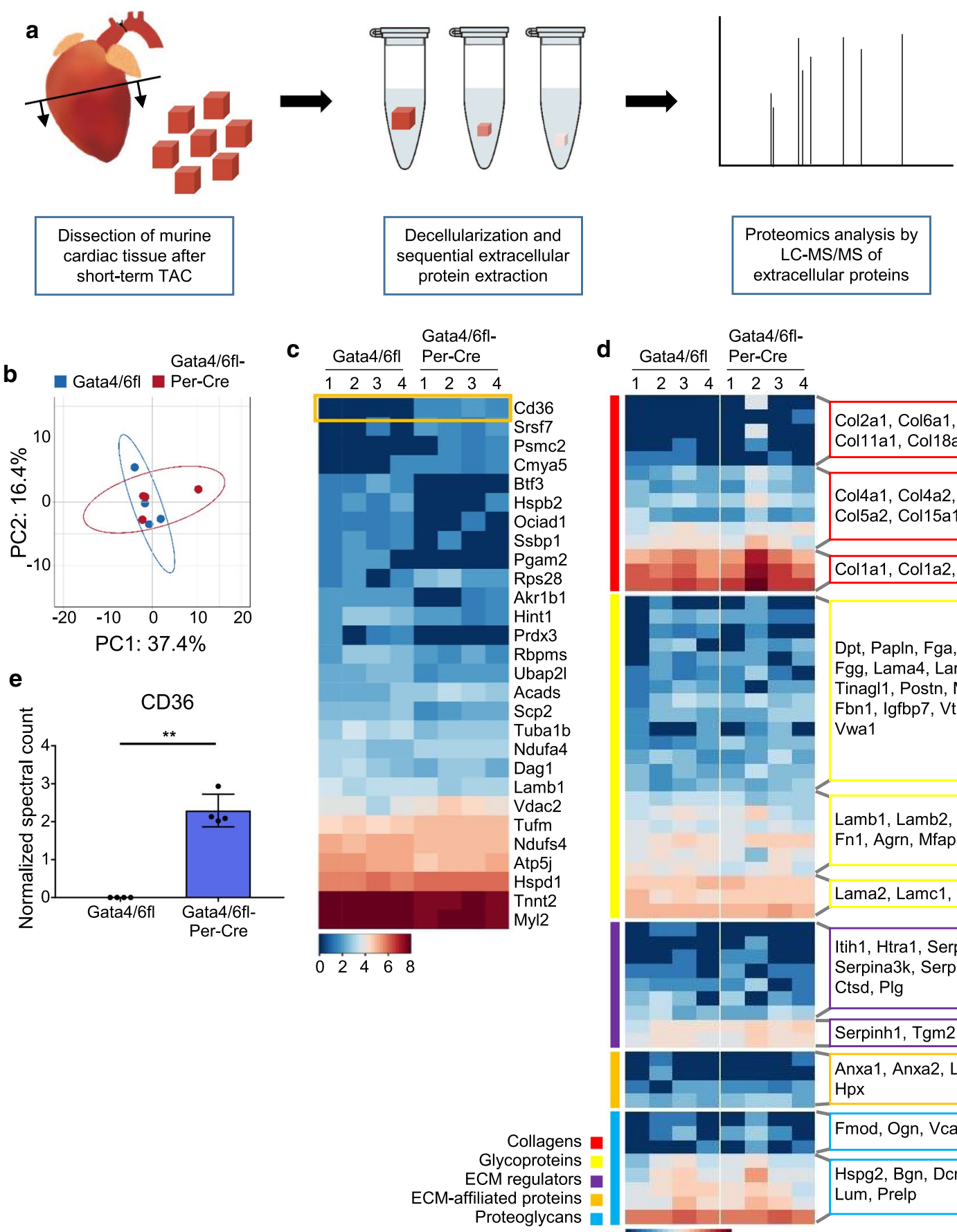

d Gata4/6fl $\begin{aligned} & \text { Gata4/6fl- } \\ & \text { Per-Cre }\end{aligned}$

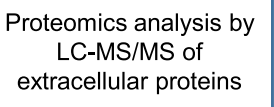

extracellular proteins

$\overline{1234} \overline{1234}$
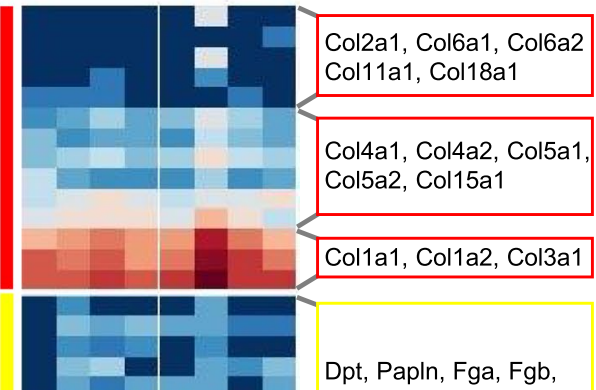

Fgg, Lama4, Lama5,

Tinagl1, Postn, Mfge8,

Fbn1, Igfbp7, Vtn,

Vwa1
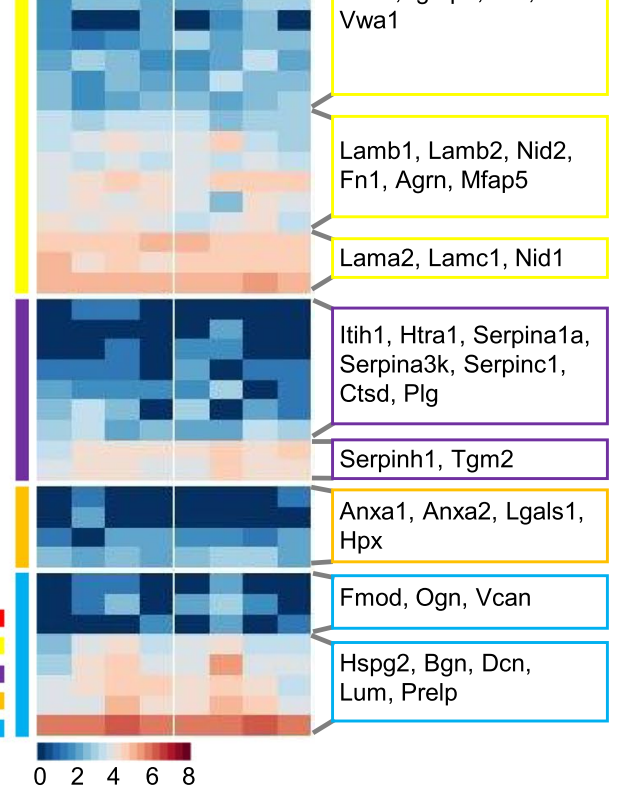

Fig. 6 Proteomic profiling of the extracellular matrix (ECM) from whole hearts of Gata4/6fl and Gata4/6fl-Per-Cre mice shows significantly higher level of the anti-angiogenic glycoprotein CD36 in mice with fibroblast-specific downregulation of Gata4 and Gata6. a Schematic overview of sample preparation for proteomic analysis of extracellular matrix components. b PCA plot of detected extracellular matrix proteins from hearts of Gata4/6 $\mathrm{fl}$ and Gata4/6fl-Per-Cre mice. c, $\mathbf{d}$ Heat map of all significantly different protein levels (c) and of important ECM components shown in color-coded clusters (d) in the cardiac ECM of Gata4/6fl and Gata4/6fl-Per-Cre mice. Detected proteins are indicated by encoding gene names. Normalized spectral counts are shown as $\log 2$ protein levels, blue color coding represents lower protein abundance, whereas red represents high protein levels. The anti-angiogenic glycoprotein CD36 was detected as the most significantly upregulated ECM protein in Gata4/6fl-Per-Cre mice compared to controls (highlighted with an orange box in c). e Normalized counts of CD36 from the ECM proteomic analysis. Data are shown as mean $\pm \mathrm{SD}$. Unpaired $t$ test with Welch's correction was used for comparison of two groups in e. ${ }^{*} p<0.01$ 
of control samples (Fig. 7f-i). Interestingly, siRNA mediated downregulation of $C d 36$ in cardiac fibroblasts with Gata4/6 double deletion also significantly improved the angiogenic response in co-cultured HUVECs (Fig. $7 \mathrm{f}-\mathrm{i}$ ). Taken together, these results point towards a novel signaling mechanism in the angiogenic response during pressure overload induced cardiac remodeling that involves not only intercellular crosstalk via secretion of angiogenesis-modulating ligands, but also extracellular deposition of signaling receptors that could modify the local ligand-availability.

\section{Discussion}

In this study, we analyzed the role of the transcription factors GATA-4 and GATA-6 in cardiac fibroblasts during pressure overload induced cardiac remodeling. While single deletion of Gata4 or Gata6 in activated cardiac fibroblasts did not exert any phenotypic effect on cardiac function, we found a more decreased systolic function and signs of aggravated heart failure in mice with combined deletion of Gata4 and Gata6 in heart fibroblasts. Histological analysis revealed an impaired angiogenic response in the hearts of mice lacking Gata4 and Gata6 in cardiac fibroblasts. These results support the in vivo relevance of intercellular signaling mechanisms upon cardiac injury. Previous investigations on the role of GATA factors have found that single deletions of Gata4 or Gata6 can be partially or completely compensated by each other in several tissues and disease states [3, 38, 44, 47]. In line with these results, single deletion of Gata4 in activated cardiac fibroblasts in our study had no detectable effect on the structural composition and function of the heart and single deletion of Gata6 even caused an increased capillary density after pressure overload. While the increased angiogenic response in Gata6 single deleted mice had no protective impact on the cardiac function, it might be a consequence of compensatory increase in GATA-4 signaling, again suggesting a functional redundancy of GATA-4 and GATA-6 in cardiac fibroblasts.

While especially GATA-4 has been extensively investigated in cardiomyocytes, where it acts as a central regulator during cardiac development, maladaptive hypertrophy and even provides regenerative properties, the fibroblast-specific functions of GATA-4 and GATA- 6 are to our knowledge largely unknown $[9,25,28,30]$. We found that among the GATA family of transcription factors, Gata4 and Gata6 show by far the highest RNA expression level in fibroblasts from adult mouse hearts and cardiac fibroblasts express at least equal, or even significantly higher levels of Gata4 and Gata6 compared to cardiomyocytes or cardiac endothelial cells. These findings confirm previous work, which had demonstrated that GATA-4 and GATA- 6 are enriched in cardiac fibroblasts versus whole heart tissue, while they are not at all expressed in skin fibroblasts [8]. In fact, Gata4 and Gata6 together with $T b \times 20$ and Hand 2 were proposed to be part of a cardiogenic gene program in these cells. Although this suggested a heart specific role of this gene program in fibroblasts, its function in the myocardial stress response remained unknown.

Considering the major contribution of activated fibroblasts to the deposition of extracellular matrix components after pressure overload, we first investigated TAC induced fibrosis. While previous studies had shown that ablation of Postn-expressing cells prevented fibrosis and preserved the heart function after myocardial infarction or pharmacological stress, we did not observe any change in the total extent or the composition of cardiac connective tissue in hearts with double deletion of Gata4/6 in activated fibroblasts compared to controls [19]. These results raised the question about additional, so far unknown functions of activated cardiac fibroblasts that could directly affect cardiac function during pathological overload. To enable continuous, heavy mechanical work, the heart strongly depends on oxidative metabolism and sustained energy supply that requires a dense network of blood vessels in close proximity to the working cardiomyocytes. While it is well established that hypertrophying cardiomyocytes stimulate capillary growth, at least in part via increased HIF- $\alpha$ and GATA-4 dependent signaling, an intercellular crosstalk between fibroblasts and myocardial endothelial cells is less investigated [12]. In this study, we show that Gata4/6 expression in cardiac fibroblasts promotes myocardial angiogenesis and thereby helps to maintain cardiac systolic function. Although we did not formally demonstrate a causal relation here, previous work had shown that reduction of cardiac angiogenesis impairs systolic heart function, while increased angiogenesis mediates the opposite $[12,17,33,36]$.

We identified two signaling pathways that mediate antiangiogenic signaling from cardiac fibroblasts to endothelial cells upon reduction of fibroblast GATA-4/-6 levels: first, we found a dramatic increase in mRNA expression levels of Angpt4 (angiopoietin-4) in cardiac fibroblasts upon Gata4/6 deletion. While previous studies reported both, pro or anti-angiogenic functions of angiopoietin-4 depending on dose and study design, we show here that recombinant angiopoietin-4 clearly inhibits endothelial cell migration and tube formation and that siRNA mediated antagonism of the increased Angpt4 RNA levels in cardiac fibroblasts restored angiogenic function in co-cultured HUVECs [22, 29]. Second, the Thbsl RNA levels as well as the expression of its receptor $C d 36$ were upregulated in Gata4/6-depleted cardiac fibroblasts. While the glycoprotein thrombospondin-1 is well established as an anti-angiogenic secreted factor especially from activated platelets, the influence of increased $C d 36$ expression levels in cardiac fibroblasts on neighboring endothelial cells remains somewhat unclear. 
a
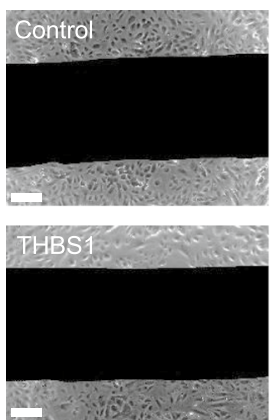

ANGPT 4:



$\mathrm{Oh}$

e

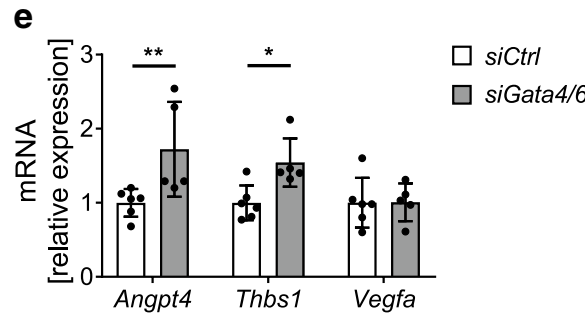

f

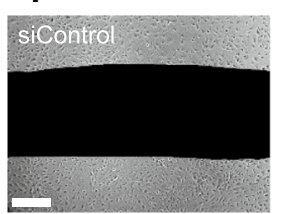

siGata4/6

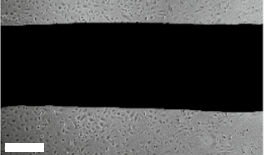

siGata $4 / 6+\operatorname{siCd} 36$

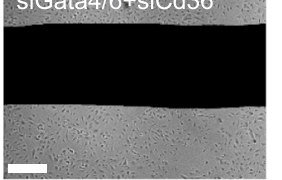

siGata4 6 +siAngpt4

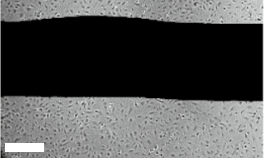

$\mathrm{Oh}$
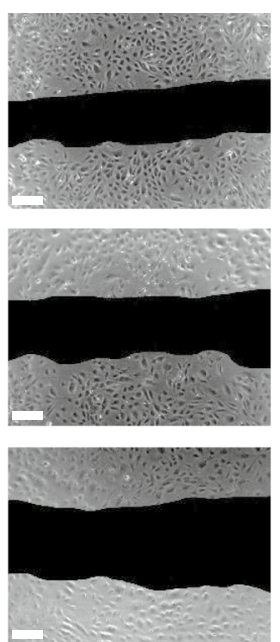

$10 \mathrm{~h}$ b
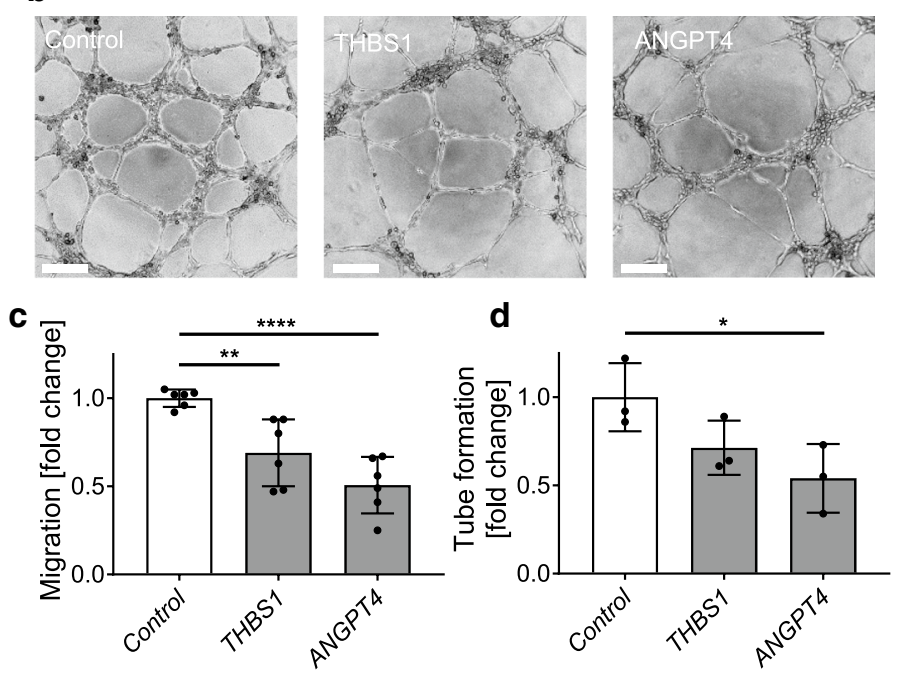

g
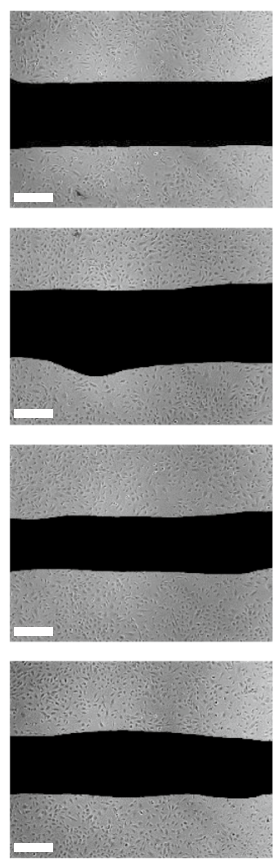

$6 \mathrm{~h}$
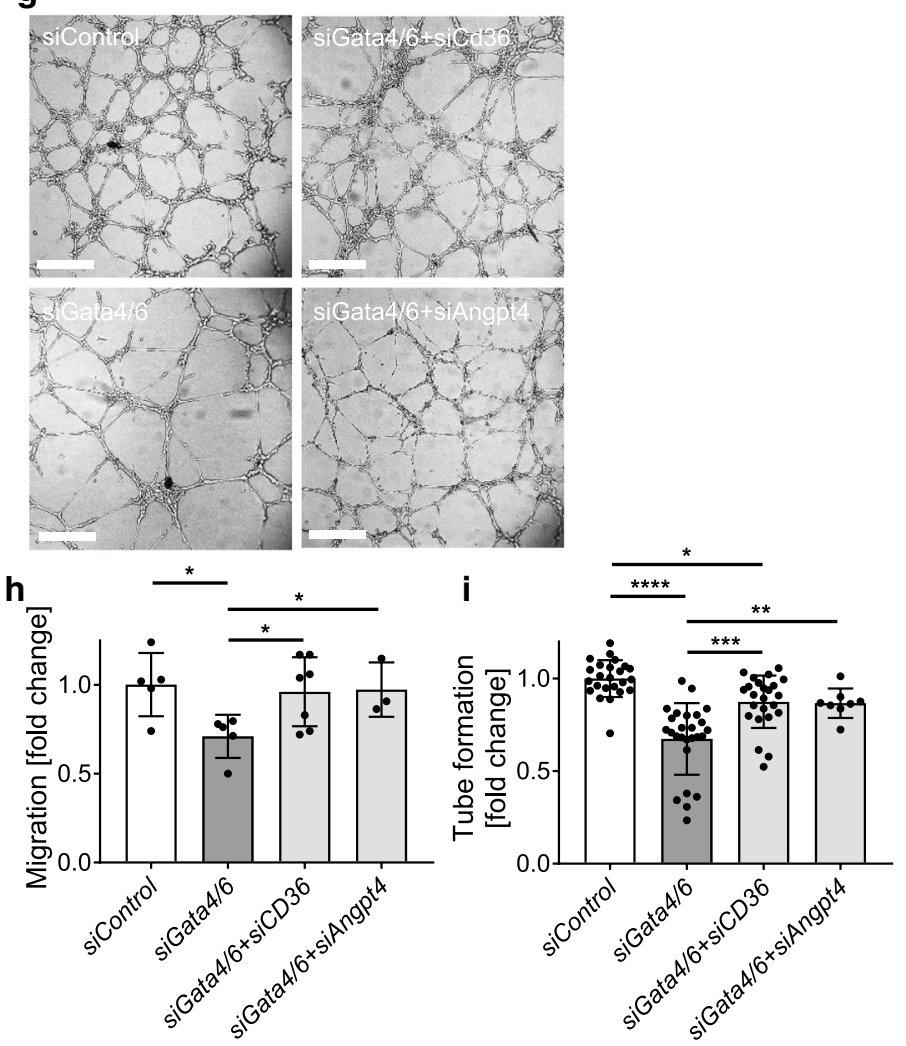
4Fig. 7 Anti-angiogenic effects of Gata4 and Gata6 downregulation in fibroblasts are mediated via CD36, thrombospondin-1 (THBS1) and angiopoietin-4 (ANGPT4). a, c Representative images of endothelial cell migration (a) and quantification (c) from scratch assays of HUVECs cultured in control medium (control) or in medium supplemented with recombinant THBS1 or ANGPT4 protein as indicated. Pictures were taken directly after scratch $(0 \mathrm{~h})$ and $10 \mathrm{~h}$ later. b, d Representative images showing the tube formation (b) and quantification of closed tubes (d) formed by HUVEC cultured on a 3D matrigel matrix. Images were taken after $8 \mathrm{~h}$ incubation in control medium (control) or medium supplemented with recombinant THBS1 or ANGPT4 protein. e Quantitative real-time-PCR of Angpt4, Thbs 1, and Vegfa in fibroblasts after siRNA mediated downregulation of Gata4 and Gata6. RNA expression levels are normalized to Gapdh. $\mathbf{f}, \mathbf{h}$ Representative images of endothelial cell migration (f) and quantification (h) from scratch assay of HUVECs in co-culture with fibroblasts. Gata4/6, Cd36 or Angpt4 were downregulated in fibroblasts by siRNA as indicated. Pictures were taken directly after scratch $(0 \mathrm{~h})$ and $6 \mathrm{~h}$ later. $\mathbf{g}$, i Representative images showing the tube formation (g) and quantification of closed tubes (i) of HUVEC/Fibroblast cocultures on a 3D matrigel matrix. Images for quantification of tube formation were taken after $8 \mathrm{~h}$ of co-culture. Scale bar $(\mathbf{a}, \mathbf{b}$, e, and f) $200 \mu \mathrm{m}$. Data are shown as mean $\pm \mathrm{SD}$. One-way ANOVA with Tukey's multiple-comparisons test $(\mathbf{c}, \mathbf{d}, \mathbf{h}$ and $\mathbf{i})$ or student's $t$ test (e) was used to test for statistical significance. ${ }^{*} p<0.05,{ }^{*} p<0.01$, $* * * p<0.001, * * * * p<0.0001$

Although we reproducibly found that counteractive downregulation of $C d 36$ in fibroblasts with lack of Gata4 and Gata6 prevented the anti-angiogenic intercellular effect, further research will be needed to fully understand the underlying mechanisms. Because we detected strongly elevated CD36 deposition in the extracellular matrix of Gata4/6 $\mathrm{fl}$ Per-Cre mice, one might speculate that it serves as scaffold protein to increase local thrombospondin levels. A recent study from Vidal et al. found a similar anti-angiogenic gene set in single-nuclei sequencing from aged cardiac fibroblasts, which among other factors, also described the glycoprotein CD36 as one of the receptors mediating intercellular fibroblast endothelial crosstalk [45]. Besides the capability to mediate anti-angiogenic properties upon thrombospondin binding, one of the first identified functions of CD36 was the strong interaction with collagen [40]. Another possible function might, therefore, be that CD36 on the surface of fibroblasts is activated by collagen to induce a paracrine gene-program, which in turn inhibits capillary growth. Indeed, $C d 36$ expressing fibroblasts counteract breast cancer cell growth in an organoid co-culture model by triggering the expression and release of unknown paracrine factors by fibroblasts [4]. However, as an in depth investigation of CD36 in cardiac fibroblasts exceeded the scope of this study, further work will be necessary to explore the mechanism of CD36 dependent effects in cardiac fibroblasts.

In this study, we focused on the transcription factors GATA-4 and GATA-6 to elucidate the role of the cardiac gene program in myocardial fibroblasts during pathological overload. Because compound deletion of Gata4 and
Gata6 in cardiac fibroblasts reduced the adaptive angiogenic response during pressure overload and entailed cardiac dysfunction, we suggest that the cardiac gene-program in fibroblasts acts to maintain a myocardium specific interstitial milieu and high capillarization of the heart. The fibroblastendothelial interface might therefore play a crucial role in the cardiac stress response and heart failure development and will require further research to enable targeted therapies in the future.

Supplementary Information The online version contains supplementary material available at https://doi.org/10.1007/s00395-021-00862-y.

Author contribution NF and JH designed the study and planned all experiments. GMD, HK, XW, HW, MS, MMM, MKK, RG, and MM performed experiments. GMD, NF, HK, XW, and HW analyzed the data. SJC provided important reagents and critically revised the manuscript. JC, MK, KCW, GD, and JB gave advice for the project, analyzed data, and critically revised the manuscript. GMD and JH wrote the manuscript. JH supervised the study. All authors read and approved the manuscript.

Funding Open Access funding enabled and organized by Projekt DEAL. This study was supported by the Deutsche Forschungsgemeinschaft through the Cluster of Excellence Rebirth (EXC 62/1 and EXC 62/3 to K.C.W., J.B., and J.H.), the Heisenberg Program (HE $3658 / 6-1$ and 2 to J.H.), the research grants HE 3658/9-1 and SFB 1366/1, A06 (to J.H.) along with National Institutes of Health grant NIH R01 HL148165 (to S.J.C.). X.W. was supported by the China Scholarship Council grant 201608080061.

Data availability All data and material supporting the findings of this study are available from the corresponding author on request. RNA-seq data are available at Gene Expression Omnibus GSE155358.

\section{Declarations}

Conflict of interest On behalf of all authors, the corresponding author states that there is no conflict of interest.

Open Access This article is licensed under a Creative Commons Attribution 4.0 International License, which permits use, sharing, adaptation, distribution and reproduction in any medium or format, as long as you give appropriate credit to the original author(s) and the source, provide a link to the Creative Commons licence, and indicate if changes were made. The images or other third party material in this article are included in the article's Creative Commons licence, unless indicated otherwise in a credit line to the material. If material is not included in the article's Creative Commons licence and your intended use is not permitted by statutory regulation or exceeds the permitted use, you will need to obtain permission directly from the copyright holder. To view a copy of this licence, visit http://creativecommons.org/licenses/by/4.0/.

\section{References}

1. Barallobre-Barreiro J, Didangelos A, Schoendube FA, Drozdov I, Yin X, Fernandez-Caggiano M, Willeit P, Puntmann VO, AldamaLopez G, Shah AM, Domenech N, Mayr M (2012) Proteomics 
analysis of cardiac extracellular matrix remodeling in a porcine model of ischemia/reperfusion injury. Circulation 125:789-802. https://doi.org/10.1161/CIRCULATIONAHA.111.056952

2. Barallobre-Barreiro J, Gupta SK, Zoccarato A, Kitazume-Taneike R, Fava M, Yin X, Werner T, Hirt MN, Zampetaki A, Viviano A, Chong M, Bern M, Kourliouros A, Domenech N, Willeit P, Shah AM, Jahangiri M, Schaefer L, Fischer JW, Iozzo RV, Viner R, Thum T, Heineke J, Kichler A, Otsu K, Mayr M (2016) Glycoproteomics reveals decorin peptides with anti-myostatin activity in human atrial fibrillation. Circulation 134:817-832. https://doi. org/10.1161/CIRCULATIONAHA.115.016423

3. Carrasco M, Delgado I, Soria B, Martin F, Rojas A (2012) GATA4 and GATA6 control mouse pancreas organogenesis. J Clin Invest 122:3504-3515. https://doi.org/10.1172/JCI63240

4. Cheng Q, Jabbari K, Winkelmaier G, Andersen C, Yaswen P, Khoshdeli M, Parvin B (2020) Overexpression of CD36 in mammary fibroblasts suppresses colony growth in breast cancer cell lines. Biochem Biophys Res Commun 526:41-47. https://doi.org/ 10.1016/j.bbrc.2020.03.061

5. Conway SJ, Molkentin JD (2008) Periostin as a heterofunctional regulator of cardiac development and disease. Curr Genomics 9:548-555. https://doi.org/10.2174/138920208786847917

6. Driscoll WS, Vaisar T, Tang J, Wilson CL, Raines EW (2013) Macrophage ADAM17 deficiency augments CD36-dependent apoptotic cell uptake and the linked anti-inflammatory phenotype. Circ Res 113:52-61. https://doi.org/10.1161/CIRCR ESAHA.112.300683

7. Froese N, Wang H, Zwadlo C, Wang Y, Grund A, Gigina A, Hofmann M, Kilian K, Scharf G, Korf-Klingebiel M, Melchert A, Signorini MER, Halloin C, Zweigerdt R, Martin U, Gruh I, Wollert KC, Geffers R, Bauersachs J, Heineke J (2018) Antiandrogenic therapy with finasteride improves cardiac function, attenuates remodeling and reverts pathologic gene-expression after myocardial infarction in mice. J Mol Cell Cardiol 122:114-124. https://doi.org/10.1016/j.yjmcc.2018.08.011

8. Furtado MB, Costa MW, Pranoto EA, Salimova E, Pinto AR, Lam NT, Park A, Snider P, Chandran A, Harvey RP, Boyd R, Conway SJ, Pearson J, Kaye DM, Rosenthal NA (2014) Cardiogenic genes expressed in cardiac fibroblasts contribute to heart development and repair. Circ Res 114:1422-1434. https://doi. org/10.1161/CIRCRESAHA.114.302530

9. Garg V, Kathiriya IS, Barnes R, Schluterman MK, King IN, Butler CA, Rothrock CR, Eapen RS, Hirayama-Yamada K, Joo K, Matsuoka R, Cohen JC, Srivastava D (2003) GATA4 mutations cause human congenital heart defects and reveal an interaction with TBX5. Nature 424:443-447. https://doi.org/10. 1038/nature01827

10. Glatz JFC, Luiken J (2018) Dynamic role of the transmembrane glycoprotein CD36 (SR-B2) in cellular fatty acid uptake and utilization. J Lipid Res 59:1084-1093. https://doi.org/10.1194/ jlr.R082933

11. Heineke J, Auger-Messier M, Correll RN, Xu J, Benard MJ, Yuan W, Drexler H, Parise LV, Molkentin JD (2010) CIB1 is a regulator of pathological cardiac hypertrophy. Nat Med 16:872879. https://doi.org/10.1038/nm.2181

12. Heineke J, Auger-Messier M, Xu J, Oka T, Sargent MA, York A, Klevitsky R, Vaikunth S, Duncan SA, Aronow BJ, Robbins J, Crombleholme TM, Molkentin JD (2007) Cardiomyocyte GATA4 functions as a stress-responsive regulator of angiogenesis in the murine heart. J Clin Invest 117:3198-3210. https:// doi.org/10.1172/JCI32573

13. Heineke J, Molkentin JD (2006) Regulation of cardiac hypertrophy by intracellular signalling pathways. Nat Rev Mol Cell Biol 7:589-600. https://doi.org/10.1038/nrm1983

14. Huang D, Yang C, Wang Y, Liao Y, Huang K (2009) PARP-1 suppresses adiponectin expression through poly(ADP-ribosyl) ation of PPAR gamma in cardiac fibroblasts. Cardiovasc Res 81:98-107. https://doi.org/10.1093/cvr/cvn264

15. Ivey MJ, Kuwabara JT, Pai JT, Moore RE, Sun Z, Tallquist MD (2018) Resident fibroblast expansion during cardiac growth and remodeling. J Mol Cell Cardiol 114:161-174. https://doi.org/ 10.1016/j.yjmcc.2017.11.012

16. Ivey MJ, Tallquist MD (2016) Defining the cardiac fibroblast. Circ J 80:2269-2276. https://doi.org/10.1253/circj.CJ-16-1003

17. Izumiya Y, Shiojima I, Sato K, Sawyer DB, Colucci WS, Walsh K (2006) Vascular endothelial growth factor blockade promotes the transition from compensatory cardiac hypertrophy to failure in response to pressure overload. Hypertension 47:887-893. https://doi.org/10.1161/01.HYP.0000215207.54689.31

18. Jimenez B, Volpert OV, Crawford SE, Febbraio M, Silverstein RL, Bouck N (2000) Signals leading to apoptosis-dependent inhibition of neovascularization by thrombospondin-1. Nat Med 6:41-48. https://doi.org/10.1038/71517

19. Kaur H, Takefuji M, Ngai CY, Carvalho J, Bayer J, Wietelmann A, Poetsch A, Hoelper S, Conway SJ, Mollmann H, Looso M, Troidl C, Offermanns S, Wettschureck N (2016) Targeted ablation of periostin-expressing activated fibroblasts prevents adverse cardiac remodeling in mice. Circ Res 118:1906-1917. https://doi.org/10.1161/CIRCRESAHA.116.308643

20. Kong P, Christia P, Saxena A, Su Y, Frangogiannis NG (2013) Lack of specificity of fibroblast-specific protein 1 in cardiac remodeling and fibrosis. Am J Physiol Heart Circ Physiol 305:H1363-1372. https://doi.org/10.1152/ajpheart.00395.2013

21. Lajiness JD, Conway SJ (2014) Origin, development, and differentiation of cardiac fibroblasts. J Mol Cell Cardiol 70:2-8. https:// doi.org/10.1016/j.yjmcc.2013.11.003

22. Lee HJ, Cho CH, Hwang SJ, Choi HH, Kim KT, Ahn SY, Kim JH, Oh JL, Lee GM, Koh GY (2004) Biological characterization of angiopoietin-3 and angiopoietin-4. FASEB J 18:1200-1208. https://doi.org/10.1096/fj.03-1466com

23. Lindsley A, Snider P, Zhou H, Rogers R, Wang J, Olaopa M, Kruzynska-Frejtag A, Koushik SV, Lilly B, Burch JB, Firulli AB, Conway SJ (2007) Identification and characterization of a novel Schwann and outflow tract endocardial cushion lineage-restricted periostin enhancer. Dev Biol 307:340-355. https://doi.org/10. 1016/j.ydbio.2007.04.041

24. Louch WE, Sheehan KA, Wolska BM (2011) Methods in cardiomyocyte isolation, culture, and gene transfer. J Mol Cell Cardiol 51:288-298. https://doi.org/10.1016/j.yjmcc.2011.06.012

25. Malek Mohammadi M, Kattih B, Grund A, Froese N, KorfKlingebiel M, Gigina A, Schrameck U, Rudat C, Liang Q, Kispert A, Wollert KC, Bauersachs J, Heineke J (2017) The transcription factor GATA4 promotes myocardial regeneration in neonatal mice. EMBO Mol Med 9:265-279. https://doi.org/10.15252/ emmm.201606602

26. Molkentin JD (2000) The zinc finger-containing transcription factors GATA-4, 5, and 6. Ubiquitously expressed regulators of tissue-specific gene expression. J Biol Chem 275:38949-38952. https://doi.org/10.1074/jbc.R000029200

27. Molkentin JD, Lin Q, Duncan SA, Olson EN (1997) Requirement of the transcription factor GATA4 for heart tube formation and ventral morphogenesis. Genes Dev 11:1061-1072. https://doi.org/ 10.1101/gad.11.8.1061

28. Oka T, Maillet M, Watt AJ, Schwartz RJ, Aronow BJ, Duncan SA, Molkentin JD (2006) Cardiac-specific deletion of Gata4 reveals its requirement for hypertrophy, compensation, and myocyte viability. Circ Res 98:837-845. https://doi.org/10.1161/01.RES. 0000215985.18538.c4

29. Olsen MW, Ley CD, Junker N, Hansen AJ, Lund EL, Kristjansen PE (2006) Angiopoietin-4 inhibits angiogenesis and reduces interstitial fluid pressure. Neoplasia 8:364-372. https://doi.org/ 10.1593/neo.06127 
30. Pu WT, Ishiwata T, Juraszek AL, Ma Q, Izumo S (2004) GATA4 is a dosage-sensitive regulator of cardiac morphogenesis. Dev Biol 275:235-244. https://doi.org/10.1016/j.ydbio.2004.08.008

31. Ring A, Le Lay S, Pohl J, Verkade P, Stremmel W (2006) Caveolin-1 is required for fatty acid translocase (FAT/CD36) localization and function at the plasma membrane of mouse embryonic fibroblasts. Biochim Biophys Acta 1761:416-423. https://doi.org/ 10.1016/j.bbalip.2006.03.016

32. Sanada S, Hakuno D, Higgins LJ, Schreiter ER, McKenzie AN, Lee RT (2007) IL-33 and ST2 comprise a critical biomechanically induced and cardioprotective signaling system. J Clin Invest 117:1538-1549. https://doi.org/10.1172/JCI30634

33. Sano M, Minamino T, Toko H, Miyauchi H, Orimo M, Qin Y, Akazawa H, Tateno K, Kayama Y, Harada M, Shimizu I, Asahara T, Hamada H, Tomita S, Molkentin JD, Zou Y, Komuro I (2007) p53-induced inhibition of Hif-1 causes cardiac dysfunction during pressure overload. Nature 446:444-448. https://doi.org/10.1038/ nature 05602

34. Scharf GM, Kilian K, Cordero J, Wang Y, Grund A, Hofmann M, Froese N, Wang X, Kispert A, Kist R, Conway SJ, Geffers R, Wollert KC, Dobreva G, Bauersachs J, Heineke J (2019) Inactivation of Sox9 in fibroblasts reduces cardiac fibrosis and inflammation. JCI Insight. https://doi.org/10.1172/jci.insight.126721

35. Shannon P, Markiel A, Ozier O, Baliga NS, Wang JT, Ramage D, Amin N, Schwikowski B, Ideker T (2003) Cytoscape: a software environment for integrated models of biomolecular interaction networks. Genome Res 13:2498-2504. https://doi.org/10.1101/ gr. 1239303

36. Shiojima I, Sato K, Izumiya Y, Schiekofer S, Ito M, Liao R, Colucci WS, Walsh K (2005) Disruption of coordinated cardiac hypertrophy and angiogenesis contributes to the transition to heart failure. J Clin Invest 115:2108-2118. https://doi.org/10.1172/ JCI24682

37. Sodhi CP, Li J, Duncan SA (2006) Generation of mice harbouring a conditional loss-of-function allele of Gata6. BMC Dev Biol 6:19. https://doi.org/10.1186/1471-213X-6-19

38. Sulahian R, Casey F, Shen J, Qian ZR, Shin H, Ogino S, Weir BA, Vazquez F, Liu XS, Hahn WC, Bass AJ, Chan V, Shivdasani RA (2014) An integrative analysis reveals functional targets of GATA6 transcriptional regulation in gastric cancer. Oncogene 33:5637-5648. https://doi.org/10.1038/onc.2013.517

39. Takeda N, Manabe I, Uchino Y, Eguchi K, Matsumoto S, Nishimura S, Shindo T, Sano M, Otsu K, Snider P, Conway SJ, Nagai R (2010) Cardiac fibroblasts are essential for the adaptive response of the murine heart to pressure overload. J Clin Invest 120:254-265. https://doi.org/10.1172/JCI40295

40. Tandon NN, Kralisz U, Jamieson GA (1989) Identification of glycoprotein IV (CD36) as a primary receptor for platelet-collagen adhesion. J Biol Chem 264:7576-7583

41. Tian Y, Morrisey EE (2012) Importance of myocyte-nonmyocyte interactions in cardiac development and disease. Circ Res 110:1023-1034. https://doi.org/10.1161/CIRCRESAHA.111. 243899
42. Timmis A, Townsend N, Gale CP, Torbica A, Lettino M, Petersen SE, Mossialos EA, Maggioni AP, Kazakiewicz D, May HT, De Smedt D, Flather M, Zuhlke L, Beltrame JF, Huculeci R, Tavazzi L, Hindricks G, Bax J, Casadei B, Achenbach S, Wright L, Vardas P, European Society of C (2020) European society of cardiology: cardiovascular disease statistics 2019. Eur Heart J 41:12-85. https://doi.org/10.1093/eurheartj/ehz859

43. van Berlo JH, Aronow BJ, Molkentin JD (2013) Parsing the roles of the transcription factors GATA-4 and GATA- 6 in the adult cardiac hypertrophic response. PLoS ONE 8:e84591. https://doi. org/10.1371/journal.pone.0084591

44. van Berlo JH, Elrod JW, van den Hoogenhof MM, York AJ, Aronow BJ, Duncan SA, Molkentin JD (2010) The transcription factor GATA-6 regulates pathological cardiac hypertrophy. Circ Res 107:1032-1040. https://doi.org/10.1161/CIRCRESAHA.110. 220764

45. Vidal R, Wagner JUG, Braeuning C, Fischer C, Patrick R, Tombor L, Muhly-Reinholz M, John D, Kliem M, Conrad T, GuimaraesCamboa N, Harvey R, Dimmeler S, Sauer S (2019) Transcriptional heterogeneity of fibroblasts is a hallmark of the aging heart. JCI Insight. https://doi.org/10.1172/jci.insight.131092

46. Vilahur G (2017) New role for CD36 in metastasis through fat intake. Cardiovasc Res 113:e16-e17. https://doi.org/10.1093/cvr/ cvx075

47. Walker EM, Thompson CA, Battle MA (2014) GATA4 and GATA6 regulate intestinal epithelial cytodifferentiation during development. Dev Biol 392:283-294. https://doi.org/10.1016/j. ydbio.2014.05.017

48. Watt AJ, Battle MA, Li J, Duncan SA (2004) GATA4 is essential for formation of the proepicardium and regulates cardiogenesis. Proc Natl Acad Sci USA 101:12573-12578. https://doi.org/10. 1073/pnas.0400752101

49. Wilkins BJ, Dai YS, Bueno OF, Parsons SA, Xu J, Plank DM, Jones F, Kimball TR, Molkentin JD (2004) Calcineurin/NFAT coupling participates in pathological, but not physiological, cardiac hypertrophy. Circ Res 94:110-118. https://doi.org/10.1161/ 01.RES.0000109415.17511.18

50. Wollert KC, Taga T, Saito M, Narazaki M, Kishimoto T, Glembotski CC, Vernallis AB, Heath JK, Pennica D, Wood WI, Chien KR (1996) Cardiotrophin-1 activates a distinct form of cardiac muscle cell hypertrophy. Assembly of sarcomeric units in series VIA gp130/leukemia inhibitory factor receptor-dependent pathways. J Biol Chem 271:9535-9545. https://doi.org/10.1074/jbc. 271.16.9535

51. Zhao R, Watt AJ, Battle MA, Li J, Bondow BJ, Duncan SA (2008) Loss of both GATA4 and GATA6 blocks cardiac myocyte differentiation and results in acardia in mice. Dev Biol 317:614-619. https://doi.org/10.1016/j.ydbio.2008.03.013

52. Zhou Y, Zhou B, Pache L, Chang M, Khodabakhshi AH, Tanaseichuk O, Benner C, Chanda SK (2019) Metascape provides a biologist-oriented resource for the analysis of systemslevel datasets. Nat Commun 10:1523. https://doi.org/10.1038/ s41467-019-09234-6 